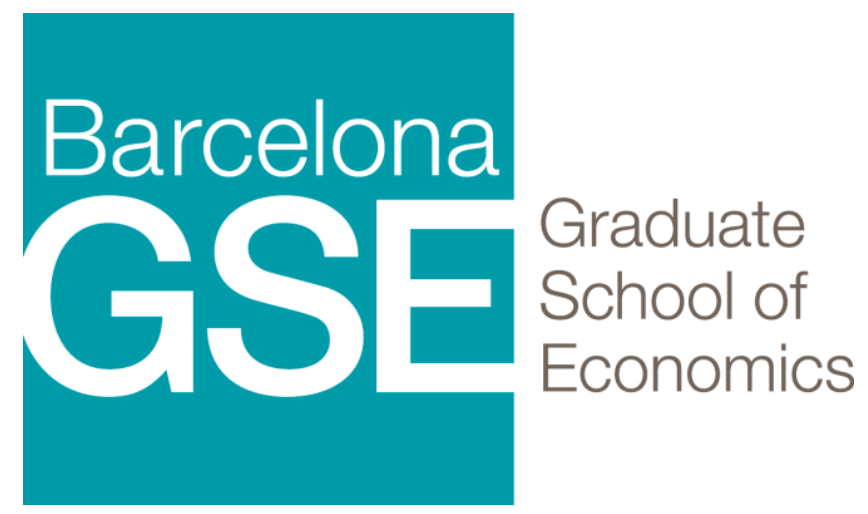

Investment, Technological Progress and Energy Efficiency

Antonia Diaz

Luis A. Puch

August 2016

Barcelona GSE Working Paper Series

Working Paper no 909 


\title{
Investment, technological progress and energy efficiency*
}

\author{
Antonia Díaz ${ }^{a}$ and Luis A. Puch ${ }^{b \dagger}$ \\ ${ }^{a}$ Universidad Carlos III de Madrid \\ ${ }^{b}$ Universitat Autònoma de Barcelona and Universidad Complutense
}

August 2016

\begin{abstract}
In this paper we propose a macroeconomic model where energy intensity at the macro level responds to changes in energy prices and technological innovations. In our theory this response depends on the interaction between the energy efficiency built in capital goods and the growth rate of Investment Specific Technological Change. ISTC reduces the cost to produce investment goods (extensive margin) and renders them more productive (intensive margin). Higher ISTC acts as an energy saving device. If energy prices stay constant, a permanent increase in the growth rate of ISTC may rise energy intensity in the long run, producing a rebound effect. This is so because the combination of higher ISTC growth rate and constant energy prices makes agents to choose less energy efficient capital goods. Our theory can be used to test when and how we should see a rebound effect in energy use at the aggregate level and can be used to test the aggregate effect of any policy aiming to reduce energy use.
\end{abstract}

Keywords: Energy efficiency, vintage capital, Investment Specific Technical Change, rebound effect JEL Classification: E22, E23, Q43.

${ }^{*}$ We thank Raouf Boucekkine and Gustavo Marrero for insightful discussions. We also thank seminar participants at the Barcelona GSE Summer Forum 2015 and the Bellaterra Seminar: Macro for useful comments. Puch thanks the Department of Economics at UAB for its support while staying as a visiting professor, year 2015-16. Financial support from the Spanish Ministerio de Economía y Competitividad (grant ECO2014-56676) is gratefully acknowledged.

${ }^{\dagger}$ Corresponding Author: Antonia Díaz, Department of Economics, Universidad Carlos III de Madrid, 28093 Madrid, Spain; E-mail: andiaz@eco.uc3m.es 


\section{Introduction}

The growing empirical literature on energy efficiency and innovation assumes that energy efficiency is a technical feature embodied in capital goods. Not only that; it also suggests that the choice of energy efficiency is determined by the interplay of energy prices and innovations that affect the cost of adopting those technologies. For instance, Newell et al. (1999) and Popp (2002) find that energy prices have a strong positive effect on adopting energy efficient technologies, whereas other authors such as Steinbuks and Neuhoff (2010), or Knittel (2011) point out that adoption of energy efficiency may be delayed by the advances in Investment Specific Technical Change (ISTC hereafter $).{ }^{1}$ Understanding this interaction is important for a variety of issues. First of all, there is a lively debate about the rebound effect, i.e., do innovations that are potentially energy saving trigger a rise in energy demand? $?^{2}$ This issue is key if we want to design policies that aim to reduce aggregate energy use without hurting economic growth. However, our current understanding of the macroeconomic rebound effect is still limited, specially in the context of innovation and growth. Second, there is an ongoing discussion about moving from "dirty" to "clean" technologies where the key question is when turning to the clean technology is profitable, (see, for instance, Acemoglu et al., 2012). To understand and estimate switching times we need to take into account, and model, the fact that our economies are becoming more efficient in the use of fossil energy over time. Finally, if energy efficiency is embodied in capital it follows that the nature and measurement of ISTC is affected by the choice of efficiency and, therefore, energy prices, as it was suggested by Gordon (1996). This paper is an attempt to contribute in this direction.

We start by giving some evidence at the macro level about the patterns of energy use and energy efficiency, for a particular economy (we use the US economy as the illustrative case) and for selected OECD countries over time. The evidence suggests that, indeed, developed economies are becoming more efficient and that the pace at which efficiency increases is affected by the interplay of the evolution of energy prices and ISTC innovations. In particular, our estimates suggest that energy use across countries falls over time but its fall may be slowed down by ISTC innovations (depending on time periods) which we take as indirect evidence of rebound effects at the macro level.

Next, we illustrate that for energy prices and ISTC to have a meaningful interaction at the

\footnotetext{
${ }^{1}$ Knittel (2011) estimates that if car quality would have not improved from 1980 to 2006, energy efficiency of both passenger cars and light trucks could have increased by nearly 60 percent from 1980 to 2006, instead of the observed meager 15 percent.

${ }^{2}$ See Frondel et al. (2012), or Gillingham et al. (2016) for a discussion on this subject.
} 
macro level we need to introduce a technological complementarity between capital and energy at the micro level. We do this by studying a decentralized version of Solow (1960) vintage capital model augmented with energy but where capital and energy are substitutes at the micro level and, therefore, the demand of energy is elastic in the short run. We call this economy the putty-putty vintage model economy. We study a decentralized version of this economy because the relative price of capital differs across vintages and the full distribution of prices is needed to obtain an expression for aggregate capital. As we already know, the aggregate version of this economy is essentially Greenwood et al. (1997). Nevertheless, by studying its disaggregated version we find that it yields counterfactual implications about energy use. For one thing, newer vintages use energy more intensely that older vintages, which is at odds with the data. The fact that new capital is more productive than older capital balances out its higher energy intensity and the result is that energy use per unit of value added at the macro level only depends on the energy price, which contradicts the macro evidence found.

Then, we move to study our benchmark economy where energy efficiency is a feature of technology. We assume that the amount of energy needed for capital to yield services is a technical requirement. This assumption renders capital heterogeneous in two dimensions: Investment Specific Technical Change (ISTC) and energy efficiency. The key trade-off is that higher energy efficiency reduces energy expenses but it comes at the cost of lower capital services and, therefore, gross output. We assume that ISTC is given exogenously whereas energy efficiency is endogenous and chosen to maximize present value of profits of that unit of capital. We call this economy the puttyclay vintage capital model economy. Here, as opposed to the putty-putty economy, the demand of energy is inelastic in the short run but by investing in more efficiency classes of capital, the long run demand turns to be elastic. This model economy is much more complex than the putty-putty economy. For one thing, service life of capital is finite now. This is so because the energy requirement acts as fixed cost in the utilization of capital. Since newer vintages are more productive than older vintages, less and less labor is placed in older vintages and, eventually, they are not used in production. The service life of capital, however, depends on the interplay of energy price and the growth rate of ISTC. This feature of the economy implies that the distribution of capital used in equilibrium changes over time which, in its turn, implies that the share of capital and labor in value added is not constant across vintages. Thus, we cannot aggregate value added across classes of capital but we show how to aggregate gross output. 
We show some properties of this economy along the balanced growth path. First of all, energy efficiency of new vintages increases over time whenever the energy price has a positive trend or there is ISTC growth at the extensive margin (that is, when technical progress reduces the cost of producing new capital in units of consumption), as the micro evidence suggests. The first implication is also present in the putty-putty economy, but not the second. The result that the extensive margin of ISTC makes profitable to choose higher energy efficiency over time is due to the complementarity between capital and energy at the micro level. More capital implies higher demand of energy. As a consequence, new capital is more efficient than older capital. Higher quality of new capital (i.e., a rise in the intensive margin of ISTC), however, allows the economy to become less efficient. This is so because the intensive margin of ISTC makes new capital more productive regardless its energy efficiency. Thus, there is a complex interaction between the energy price and ISTC. To give a sense of the quantitative importance of this interaction we have calibrated our benchmark economy and the putty-putty economy to match selected statistics of the US economy. Measurement is very instructive since, in the putty-clay economy, as opposed to the putty-putty economy, not all movements in the relative price of investment (adjusted by quality) can be attributed to changes in ISTC. Rather, those movements also depend on the energy efficiency of capital which, in its turn, depends on the interaction of ISTC and energy prices, as Gordon (1996) suggested.

Our quantitative exercises yield two key findings about the long run effects of changes in energy prices and ISTC. First, a permanent change in the level of the energy price produces a permanent change of about the same magnitude in aggregate value added per unit of energy used in both models economies (putty-putty and putty-clay). Thus, the effect is pretty linear. Second, a permanent increase in the ISTC growth rate does not affect value added per unit of energy use in the puttyputty economy. It does affect, though, this ratio in the putty-clay economy. In the case in which agents do not expect the energy price to increase there is a rebound effect, i.e., the amount of value added per unit of energy use falls permanently. This is so because the gains in productivity brought by higher ISTC growth offset the increased burden of higher energy expenditures which makes agents to choose less energy-efficient capital. Nevertheless, if agents expect the energy price to increase permanently, there is no rebound effect and the higher efficiency of the capital stock reduces energy use per unit of value added. Hence, our theory can be used to test the determinants of the existence of rebound effects at the macroeconomic level.

Finally, we give a sense of the dynamic response of our economy by means of an approximate 
economy where capital is always used in production even if is no longer profitable. This approximate economy is Greenwood et al. (1997) with the explicit consideration of energy as an input, and where changes in energy efficiency amount to changes in the depreciation rate of the stock of capital. We show that the quantitative differences between this approximate economy and our benchmark economy are negligible and, therefore, can be used to study quantitatively short run effects of the interaction of ISTC and energy prices using standard computational methods. We show that the short run response of the putty-putty economy is equal to its long run response. Hence, there is no meaningful interaction of ISTC and energy prices at the macro level whenever there is no complementarity of capital and energy. In our proxy putty-clay economy, however, there is a non monotonous response to changes in ISTC. In particular, we learn that the rebound effect is a long run effect. In the short run any increase in the ISTC growth rate produces a macro gain in energy efficiency. Thus, this is important if we want to assess the effect of any policies that affect the pace of innovations in ISTC on aggregate energy use.

We view ours as a theory of investment where we make explicit the determinants of energy use and energy-saving technical change. We are not the first in studying the implications of the micro complementarity of capital and energy at the macro level. An early attempt to reconcile the shortrun response to energy price changes with a long-run adjustment of energy aggregates is in Atkeson and Kehoe (1999). In their model, higher efficiency comes at the cost of less capital services and, therefore, less output. Building upon the idea of heterogeneous capital, Díaz et al. (2004) discuss a model economy where capital is putty-putty but there are adjustment costs in investment at the aggregate level. In that economy, energy efficiency comes at an output cost. These authors, however, abstracted from ISTC which is key to study the determinants of macroeconomic rebound effects. Ours has a flavor of a theory of directed technical change, as Acemoglu (2002), and Acemoglu et al. (2012), although the former studies the determinants of skill biased technical change whereas the latter focus on the substitution from environmental damaging to friendly technologies. A related work to ours is that by Hassler et al. (2012), who build on the tradition of Pindyck and Rotemberg (1983) and use an aggregate production function to calibrate a measure of energy-saving technical change consistent with the US experience, although they ignore the existence of ISTC.

The organization of the paper is as follows. Section 2 gives some evidence at the macro level about the patterns of energy use and energy efficiency. Section 3 describes the model economy where capital and energy are substitutes and describes the decentralization of the economy. Section 
4 describes our model economy and presents some properties of equilibria and the balanced growth path. Section 5 presents our main results about the quantitative properties of our model economy in connection with the evidence. Section 6 concludes.

\section{Energy use and energy efficiency and the macroeconomy}

To focus ideas we present some facts about energy use and energy efficiency at the aggregate level. We start examining the US economy as illustrative case.

If energy efficiency is embodied in capital goods, it must be the case that the more efficient the stock of capital, the higher must be the aggregate capital to energy ratio. Moreover, if the economy grows along a balanced growth path, higher energy efficiency implies higher final output per unit of energy. Figure 1 shows that this seems to be the case in the US economy. A full explanation of the sources and methods used in our data construction is given in Appendix A.

Figure 1(a) shows the ratio of aggregate Value Added, $V A$, net of value added of energy producing sectors, to energy consumption, $E$. The aggregate energy $E$ is a composite of total consumption of oil, coal, natural gas and electricity measured in units of British Termal Units. Renewable energy is not included. We call this ratio the inverse of energy use and it is closely related to a statistic called energy intensity, reported by the World Bank (see Figure 2), which measures the amount of GDP per units of energy consumed in millions of Joules. The ratio $V A / E$, in logs, grew at an annual average rate of 1.54 percent. In the picture, the dashed line shows this linear trend. Figure 1 (b) shows the evolution of the ratio of capital to energy, $K / E$, which is our measure of aggregate efficiency. The statistic $K$ is the value of the stock of capital in units of final output. We have also added a linear trend which grows at the rate of the ratio $V A / E$. We also show the capital to value added ratio $K / V A$, not logged since it has no trend. Both pictures together suggest that the US economy grows along a balanced growth path. In fact, if the U.S. were growing along a balanced growth path without any disturbance, the ratios $K / E$ and $V A / E$ should have the same growth rate. During the period 1960-2010 the growth rate of $V A / E$ was 1.54 percent, whereas that of $K / E$ was 1.60 percent.

Figure 1(c) shows the relative price of energy, $p^{e}$. It is the weighted average of the relative price of a BTU in units of non durable goods and services, in logs. We have also added a linear 
trend growing at 1.54 percent. As we can see, the energy price has significant fluctuations. For the period 1960-2010, the average growth rate of the price was 2.10 percent. Since the price fluctuates very much whereas energy use, $E / V A$, does not, the energy share, $p^{e} E / V A$ (not in logs) takes all the fluctuations: the average for the entire period is 4.76 percent, it reaches a maximum of 8.86 percent in 1981 and a minimum of 3.19 in 1998. Finally, we have plotted the inverse of the relative price of investment goods taken from Rodríguez-López and Torres (2012) who update the work by Cummins and Violante (2002). It is adjusted by quality. The growth rate of the inverse of the price is a measure of technical progress. Notice that there is an acceleration after 1982, period after which the price falls at the annual rate of 2.39. Prior to that date, the rate was 0.79 percent. Summarizing, the US economy seems to grow along a balanced growth path, it is becoming more efficient and its energy use (per unit of value added) is falling, even during the periods in which the fall in the energy price is very intense, as during the period 1981-1998. As a result, the capital to value added ratio and the energy share have no trend and the relative price of investment goods fall at a constant rate.

Figure 2 shows a related statistic for a sample of countries. The statistic shown is GDP per unit of Million of Jules consumed in the economy and it is reported by the World Bank. As we can see, there is substantial differences in the time series behavior of this statistic across countries, but the general pattern is that energy use seems to be falling over time, as it is the case in the US economy, although with significant exceptions, as the cases of Spain and Portugal illustrate. Hence, we think that we can safely assume that the gain in efficiency seen in the US economy is a general pattern of the process of economic growth in OECD countries.

To give further evidence on this issue we have tested that, indeed, there is a trend in the ratio of aggregate GDP to energy use across countries. Table 1 and its continuation in Table 2 show a battery of tests on the correlations of the ratio of GDP to energy use for a panel of OECD countries for the period 1970-2010. We use intervals of five years to eliminate high frequency movements in the ratio energy used per unit of GDP. Moreover, since we are interested in long run changes in energy use we regress the growth rate of energy use per unit of GDP (in logs) on the previous level of the ratio $e_{t-1} / g d p_{t-1}$ (in logs, too), controlling for the GDP level and growth rate and an array of dummy variables, $\left(\operatorname{dum}_{75}, \ldots, \mathrm{dum}_{10}\right)$. As we can see in column (1) (and the rest of columns) in Table 1, the time dummies after 1975 are significant and have a negative impact on the growth rate of the ratio $e_{t} / g d p_{t}$. Since we control for the lagged level of the ratio, we can conclude that energy 
use per unit of output, indeed, is decreasing over time and that it is a pattern observed across countries. One may wonder which effect are the time dummies picking. Our first candidate is the energy price. Notice that the effect of the time dummies becomes relevant after 1980, time after which the energy price experiences persistent upsurges. Next, we add as regressors the (lagged) level of the relative price of investment goods, $q_{t-1}$, and its contemporaneous growth rate. We include them separately to ensure that, indeed, we capture the effect of the 5 years change in the relative price of capital. This variable is our proxy for ISTC. Hence, it captures the effect of ISTC on energy efficiency, as measured by the ratio of energy use per unit of GDP. Column 7 of Table 1 shows the effect of ISTC, as measured by changes in the relative price of investment goods, $q_{t-1}$, and its growth rate, $q_{t} / q_{t-1}$ on the growth rate of energy use to GDP ratio when we omit the time dummies. The effect is positive, which implies that an increase in the growth rate of ISTC (a reduction in the growth rate of the price) reduces the rate at which the ratio energy to GDP grows. That is, ISTC innovations are energy saving. However, whenever we include the time dummies (column 6), the sign of the correlation becomes negative. Although the effect is significant at the 10 percent

level, we take this change in the sign as potential evidence of the rebound effect at the macro level. Notice that, when considering the energy and sectoral mixes, $q_{t} / q_{t-1}$ becomes less significant (and also $\left.q_{t-1}\right)$. Interestingly, moving the share in the energy mix from coal to renewables (mixc5, it should reflect lower energy intensity) reduces growth in energy intensity. Similarly occurs when moving from industry to transport (mixcf2; also agriculture, mixcf5) at the sectoral mix level.

Summarizing, we find this evidence suggestive of energy efficiency at the macro level increasing over time, but the pace at which it increases is affected by ISTC innovations, which may lead even to an aggregate rebound effect, although the evidence is not conclusive on this respect. Putting together this macroeconomic evidence and the micro evidence reported by authors such as Steinbuks and Neuhoff (2010), or Knittel (2011), as well as the estimates on the rebound effect by Frondel et al. (2012), or Gillingham et al. (2016) we conclude that a macroeconomic model economy is needed to study the aggregate response of an economy to the interaction of energy prices and ISTC.

\section{$3 \quad$ Putty-putty energy efficiency of vintage capital}

To illustrate how energy efficiency and ISTC interact, we present first a version of Solow (1960) vintage capital model with the explicit consideration of the need of energy for capital to yield 
services. Our aim here is to show that if energy efficiency is not modeled as a feature of technology the aggregate economy cannot capture the patterns of energy use and aggregate efficiency observed in the data. Additionally, we present here the market arrangements that we will keep throughout this paper for ease of exposition. We present a market economy instead of a planned economy because, typically, the literature on ISTC and growth have used the relative prices of investment to infer the rate at which innovations embodied in capital grows over time. Thus, we need to tackle the decentralized economy. We focus on the economy without uncertainty. We will refer to this model economy as the putty-putty vintage capital economy.

\subsection{The environment}

\subsubsection{Preferences}

There is a continuum of households that seek to maximize expected discounted lifetime utility,

$$
\sum_{t=0}^{\infty} \beta^{t} \frac{c_{t}^{1-\sigma}}{1-\sigma}, \beta \in(0,1), \sigma>0
$$

where $c_{t}$ is consumption. Households are endowed with one unit of time every period.

\subsubsection{Technology and the physical environment}

Production of the unique final good is carried out at a continuum of plants. A plant is created by installing one unit of capital. Plants are indexed by the vintage of the unit of capital installed, which is denoted by $z$. Output is produced combining labor and the services of the unit of capital installed according to the technology

$$
y_{t}(z)=A_{t} \kappa_{t}(z)^{\alpha} h_{t}(z)^{1-\alpha}, z \leq t
$$

with $\alpha \in(0,1) . A_{t}$ is the neutral technical change factor that grows at the constant rate $\gamma_{a}$; whereas $\kappa_{t}(z)$ and $h_{t}(z)$ are, respectively, the amount of services provided by the unit of capital installed and the amount of labor services employed in the plant. The vintage of capital is given by the date at which the unit of capital was produced. Thus, $z \leq t$. The amount of services yielded by the unit 
of capital depends on energy use. Formally,

$$
\kappa_{t}(z)=(1+\lambda)^{z(1-\phi)} e_{t}(z)^{\phi}, z \leq t
$$

where $\phi<1$. $(1+\lambda)^{t}$ measures the change in quality of capital goods over time. Expression (3.3) shows that energy efficiency is not a feature of capital; it rather changes with market conditions. This is why we label this economy as the putty-putty vintage capital model economy, because capital is putty-putty along its energy efficiency dimension.

There is a technology that allows agents to transform final good of period $t$ into $(1+\theta)^{t}$ units of capital of vintage $t+1$. Thus, as it is standard in the literature, we take the view that investment specific technological change (ISTC) not only brings higher quality, given by $\lambda$, but also the production of capital goods becomes increasingly efficient with the passage of time (see Greenwood et al., 1997). We could think of changes in $\lambda$ as innovations that affect the intensive margin of ISTC, whereas changes in $\theta$ are meant to capture innovations in the extensive margin of ISTC. Finally, we will denote as $x_{t}$ the amount of final good invested in capital of vintage $t+1$ that will be operated at period $t+1$.

The number of plants of vintage $z$ is equal to the amount of capital of that vintage, $k_{t}(z)$. Capital is irreversible; that is, capital of vintage $z_{1}$ cannot be converted in capital of vintage $z_{2}$. The plant, though, can be left idle by allocating neither energy nor labor. Finally, once production has taken place, the plant faces a positive probability of death, $\varpi \in[0,1]$, which is i.i.d. across plants. This death implies the destruction of the unit of capital and it plays the role of physical depreciation of capital. Therefore,

$$
k_{t}(z)=(1-\varpi)^{t-z} k_{z}(z), z \leq t
$$

Notice that $k_{t}(z)$ is the amount of capital of vintage $z \leq t$ available at the beginning of period $t$, before production and depreciation has taken place.

\subsubsection{Differences with Solow (1960)}

At this point it will be useful to emphasize the differences with the original formulation of Solow (1960). The original vintage capital model abstracts from the effect of intermediate inputs, such us 
energy. As a consequence, capital services only depend on capital vintage, $\kappa_{t}(z)=(1+\lambda)^{z}$, for all $t \geq z$; that is, Solow (1960) is our economy setting $\phi \rightarrow 0$. This implies that $y_{t}(z)$ denotes, at the same time, gross output and value added at the plant level. There are some other minor differences such as that our plants only need one unit of capital but this assumption is not restrictive since the technology displays constant returns to scale in capital and labor. As it will be clear in Section 3.3.2, this formulation is convenient to characterize the price of capital of any vintage.

\subsection{Market arrangements}

We assume that energy is entirely bought in an international market at an exogenously given price $p_{t}^{e}$. We assume that there is no international borrowing and lending. In absence of an international credit market we can think of the price of energy as given by nature.

Households are the owners of the plants and, therefore, of the capital installed. There is a market for plants that opens at the end of the period, once profits have been realized. Notice, though, that capital is not traded since it is already installed in a plant and it cannot be reallocated. Since there is a one to one correspondence between plants and units of capital, the price of a plant is also the price of the unit of capital installed, $p_{t}(z)$. We further assume that all households start out with the same amount of shares of the plants installed. They can trade a one period risk free asset which is in zero net supply.

\subsubsection{The plant's problem}

The plant has the usual problem of profit maximization:

$$
\begin{array}{ll}
\pi_{t}(z)=\max _{\begin{array}{r}
y_{t}(z) \geq 0, h_{t}(z) \geq 0, \\
e_{t}(z) \geq 0, \kappa_{t}(z) \geq 0
\end{array}} & y_{t}(z)-w_{t} h_{t}(z)-p_{t}^{e} e_{t}(z) \\
\text { s. t. } & y_{t}(z) \leq A_{t} \kappa_{t}(z)^{\alpha} h_{t}(z)^{1-\alpha}, \\
& \kappa_{t}(z) \leq(1+\lambda)^{z(1-\phi)} e_{t}(z)^{\phi} .
\end{array}
$$




\subsubsection{The production of new capital}

The production of capital uses a linear technology in final good. The new capital produced is the new vintage $t+1$, which yields higher services. We denote as $\pi_{t}^{x}=\max _{x_{t} \geq 0}\left[p_{t}(t+1)(1+\theta)^{t}-1\right] x_{t}$ the profit of the sector.

\subsubsection{The household's problem}

Plants of any class can be traded at the individual level. New investment, however, comes in new vintage - it is a technological restriction. The household's problem can be written in the following way:

$$
\begin{array}{ll}
\max & \sum_{t=0}^{\infty} \beta^{\frac{t_{t}^{1-\sigma}}{1-\sigma}} \\
\text { s. t. } & c_{t}+\sum_{z=-\infty}^{t+1} p_{t}(z) k_{t+1}(z)+a_{t+1} \leq w_{t} \hbar+\left(1+r_{t}\right) a_{t}+\sum_{z=-\infty}^{t}\left[(1-\varpi) p_{t}(z)+\pi_{t}(z)\right] k_{t}(z)+\pi_{t}^{x}, \\
& k_{t+1}(t+1) \geq 0, \\
& a_{t+1} \geq \underline{a}, \\
& k_{0}(z), z \leq 0, a_{0}, \text { and energy prices given. }
\end{array}
$$

\subsubsection{Definition of equilibrium}

An equilibrium for this economy given the sequence of energy prices, $\left\{p_{t}^{e}\right\}_{t=0}^{\infty}$, is a sequence of prices $\left\{\left\{p_{t}(z)\right\}_{z=-\infty}^{t+1}, w_{t}, r_{t}\right\}_{t=0}^{\infty}$, an allocation $\left\{c_{t},\left\{k_{t+1}(z)\right\}_{z=-\infty}^{t+1}, a_{t+1}\right\}$ for each consumer, an allocation for each plant of vintage $z,\left\{y_{t}(z), h_{t}(z), \kappa_{t}(z), e_{t}(z)\right\}_{z=-\infty}^{t}$, and an investment plan, $x_{t}$, such that:

1. $\left\{c_{t},\left\{k_{t}(z)\right\}_{z=-\infty}^{t+1}, a_{t+1}\right\}$ solves the household's problem shown in (3.6) given the sequence of prices,

2. $\left\{y_{t}(z), h_{t}(z), e_{t}(z)\right\}_{z=-\infty}^{t}$, solves the plant's problem given the sequence of prices,

3. the price of investment satisfies $p_{t}(t+1) \leq(1+\theta)^{-t}$,

4. markets clear,

(a) the bond is in zero net supply, $a_{t+1}=0$, 
(b) the labor market clears, $1=\sum_{z=-\infty}^{t} k_{t}(z) h_{t}(z)$,

(c) the market of new capital clears, $k_{t+1}(t+1)=(1+\theta)^{t} x_{t}$,

(d) the final good market satisfies $c_{t}+x_{t}=\sum_{z=-\infty}^{t} k_{t}(z) y_{t}(z)$,

5. and the law of motion of capital of vintage $z$ is $k_{t}(z)=(1-\varpi)^{t-z}(1+\theta)^{z-1} x_{z-1}$, for all $t \geq z$, for all $t$.

\subsection{Equilibrium properties}

Here we present the properties of equilibrium that will allow us to aggregate the economy and analyze its macroeconomic implications in terms of energy efficiency and energy use.

\subsubsection{Allocation of inputs at the plant level}

Solving the plant's problem we find that energy demand at the plant level is a function of aggregates and the vintage of the unit of capital installed,

$$
e_{t}(z)=\left[\frac{\phi \alpha}{p_{t}^{e}} A_{t}\left(\frac{(1-\alpha) A_{t}}{w_{t}}\right)^{\frac{1-\alpha}{\alpha}}\right]^{\frac{1}{1-\phi}}(1+\lambda)^{z}
$$

This demand function says that younger plants demand more energy than older plants. The energy share in gross output at the plant level is constant over time and equal to $\phi \alpha$. This demand function is separable in time and vintage, which implies that the distribution of energy use across vintages does not depend on time and, particularly, on the energy price. It only depends on how embodied technical change rises with the vintage. This feature of energy demand will be key to characterize the equilibrium allocation. This also implies that the distribution of capital services, labor demand and gross output across vintages only depends on the vintage,

$$
\frac{\kappa_{t}\left(z_{1}\right)}{\kappa_{t}\left(z_{2}\right)}=\frac{h_{t}\left(z_{1}\right)}{h_{t}\left(z_{2}\right)}=\frac{y_{t}\left(z_{1}\right)}{y_{t}\left(z_{2}\right)}=(1+\lambda)^{z_{1}-z_{2}}
$$

In particular, changes in energy prices and the extensive margin of ISTC, $(1+\theta)^{t}$, do not affect the allocation of labor and energy across plants. Not only that, but the distribution of profits across vintages does not depend on time either. This is so because the profit of the plant is the share of 
capital net of energy expenditure,

$$
\pi_{t}(z)=\alpha(1-\phi) y_{t}(z)
$$

The direct consequence is that value added at the plant level is a linear function of gross output. We can write value added at the plant level directly as a function of capital and labor taking into account that the demand of energy is $e_{t}(z)=\alpha \phi y_{t}(z) / p_{t}^{e}$,

$$
v a_{t}(z)=(1-\alpha \phi)\left[\frac{\alpha \phi}{p_{t}^{e}} A_{t}^{\frac{1}{\alpha \phi}}\right]^{\frac{\alpha \phi}{1-\alpha \phi}}(1+\lambda)^{z \widetilde{\alpha}} h_{t}(z)^{1-\widetilde{\alpha}}, \widetilde{\alpha}=\frac{\alpha(1-\phi)}{1-\alpha \phi} .
$$

Thus, at the plant level, changes in the energy price have the same effect that changes in neutral progress.

\subsubsection{The price of capital and the aggregation of capital}

The problem of the firms producing investment goods imply that capital of the latest vintage, $t+1$, is produced whenever $p_{t}(t+1) \geq(1+\theta)^{-t}$. Equilibrium dictates that $p_{t}(t+1) \leq(1+\theta)^{-t}$. Typically, there will be investment in equilibrium, thus, $p_{t}(t+1)=(1+\theta)^{-t}$. Solving the household's problem we find that the household must be indifferent between investing in plants or in bonds,

$$
1+r_{t+1}=\frac{(1-\varpi) p_{t+1}(z)+\pi_{t+1}(z)}{p_{t}(z)}, \text { for all } z \leq t+1
$$

Since profit of a plant of vintage $z$ is always positive, recursively we find that the price is the present value of all future dividends,

$$
p_{t}(z)=\sum_{i=1}^{\infty} \frac{(1-\varpi)^{i-1}}{\prod_{j=1}^{i}\left(1+r_{t+j}\right)} \pi_{t+i}(z)
$$

Since $\pi_{t+i}(z)=(1+\lambda)^{z-t-1} \pi_{t+i}(t+1)$, for all $z \leq t+1$, it follows that the price of capital of vintage $z$ at time $t$ in units of consumption good is

$$
p_{t}(z)=(1+\lambda)^{z-t-1}(1+\theta)^{-t}
$$


Notice that the rate at which the price of a particular vintage decays over time depends on both sources of technical change, $p_{t}(z) / p_{t-1}(z)=[(1+\lambda)(1+\theta)]^{-1}$, but, differences in the market price across vintages at any given period only depend on quality, not on productivity in the investment sector, as measured by the growth rate of the extensive margin of ISTC, $\theta$. This information is lost once we aggregate capital. Also notice that the ratio $p_{t}(z) / p_{t}(t+1)=(1+\lambda)^{z-t-1}$ can be interpreted as the Tobin's $q$, since it measures the market value of vintage $z$ over the cost of replacing capital. Finally, we should take into account that, according to this theory, energy prices do not affect the relative price of capital goods.

In order to be consistent with NIPA and other National Accounts, we define the aggregate capital stock as the value of capital in units of consumption good of period $t-1$. In our notation this is

$$
\mathbf{k}_{t}=\sum_{z=-\infty}^{t} p_{t-1}(z) k_{t}(z)=\sum_{z=-\infty}^{t}\left(\frac{1-\varpi}{(1+\lambda)(1+\theta)}\right)^{t-z} x_{z-1}
$$

Such an aggregate measure of the stock of capital can be written as the law of motion of capital

$$
\mathbf{k}_{t}=x_{t-1}+\frac{(1-\varpi)}{(1+\lambda)(1+\theta)} \mathbf{k}_{t-1}
$$

The depreciation rate, $\delta=1-(1-\varpi) /[(1+\lambda)(1+\theta)]$, includes physical decay as well as economic obsolescence. We can also define quality-adjusted capital as the value of aggregate capital in units of a base vintage,

$$
\kappa_{t}=\sum_{z=-\infty}^{t} \frac{p_{t-1}(z)}{p_{t-1}(0)} k_{t}(z)=\sum_{z=-\infty}^{t}(1-\varpi)^{t-z}(1+\lambda)^{z}(1+\theta)^{z-1} x_{z-1}=(1+\lambda)^{t}(1+\theta)^{t-1} \mathbf{k}_{t}
$$

It follows that the price of capital adjusted by quality is $p_{t}^{\kappa}=(1+\lambda)^{-t-1}(1+\theta)^{-t}$.

\subsubsection{The aggregate economy}

First, we need to find aggregate value added, which is

$$
\mathbf{v a}_{t}=\sum_{z=-\infty}^{t} k_{t}(z) v a_{t}(z)=\sum_{z=-\infty}^{t} k_{t}(z)(1+\lambda)^{z-t} v a_{t}(t)
$$


After some manipulations and using (3.8), we find that the expression of aggregate value added as a function of the aggregate stock of capital is

$$
\mathbf{v a}_{t}=Z_{t} \mathbf{k}_{t}^{\widetilde{\alpha}} h_{t}^{1-\widetilde{\alpha}}, \widetilde{\alpha}=\frac{\alpha(1-\phi)}{1-\alpha \phi} .
$$

Total Factor Productivity, $Z_{t}$, is a function of neutral technological progress, the energy price and ISTC:

$$
Z_{t}=(1-\alpha \phi)\left[\frac{\alpha \phi}{p_{t}^{e}} A_{t}^{\frac{1}{\alpha \phi}}\right]^{\frac{\alpha \phi}{1-\alpha \phi}}\left[(1+\lambda)^{t}(1+\theta)^{t-1}\right]^{\widetilde{\alpha}}
$$

Thus, in this economy the effect of energy prices is equivalent to a change in neutral progress. This representation of the aggregate economy is exactly Greenwood et al. (1997) where energy use has been made explicit. Here, as we have discussed before, changes in the energy price are tantamount to changes in neutral progress.

\subsection{Energy use and efficiency at the macro level}

In this economy the share of energy is constant at the plant level and independent of the vintage. Thus, the share of energy in the aggregate is

$$
\frac{p_{t}^{e} \mathbf{e}_{t}}{\mathbf{v a}_{t}}=\frac{p_{t}^{e} e_{t}(z)}{y_{t}-p_{t}^{e} e_{t}(z)}=\frac{\alpha \phi}{1-\alpha \phi} \text {. for all } z \leq t
$$

Consequently, value added per unit of energy used at the plant level and at the aggregate level do not depend on ISTC and it tracks the energy price,

$$
\frac{\mathbf{v a}_{t}}{\mathbf{e}_{t}}=\frac{y_{t}(z)-p_{t}^{e} e_{t}(z)}{e_{t}(z)}=\frac{p_{t}^{e}(1-\alpha \phi)}{\alpha \phi}, \text { for all } z \leq t
$$

These two statistics of the model are at odds with the data, where value added per unit of energy use increases steadily, even in periods in which the energy price is falling, and the share fluctuates almost as much as the price of energy does. Nevertheless, this model delivers predictions that are consistent with some long run trends of the US economy. Assume that the energy price grows at a constant rate. Along the balanced growth path $\mathbf{v a}_{t} / \mathbf{e}_{t}$ grows at the same rate that the price and the energy share is constant. 
Let us turn now to energy efficiency, as measured by the capital (measured in units of output) to energy ratio. Using expression (3.7), the value of this ratio at the plant level is

$$
\frac{p_{t-1}(z)}{e_{t}(z)}=\left[\frac{\phi \alpha}{p_{t}^{e}} A_{t}\left(\frac{(1-\alpha) A_{t}}{w_{t}}\right)^{\frac{1-\alpha}{\alpha}}\right]^{\frac{-1}{1-\phi}}(1+\lambda)^{-t}(1+\theta)^{-t-1}, \text { for all } z \leq t
$$

Hence, all plants operate with the same energy efficiency when capital is measured in units of output. This is so because the relative price of capital falls with the vintage. This is at odds with the micro evidence presented in the Introduction, which suggests that capital goods of different vintages have different levels of energy efficiency. In the model the aggregate capital to energy ratio can be easily written as

$$
\frac{\mathbf{k}_{t}}{\mathbf{e}_{t}}=\frac{p_{t}^{e}(1-\alpha \phi)}{\alpha \phi} \frac{\mathbf{k}_{t}}{\mathbf{v a}_{t}}
$$

Thus, energy efficiency depends on the energy price and the capital to value added ratio. Along a balanced growth path the capital to value added ratio is constant. Along that path the capital to energy ratio tracks the energy price. This model economy has implications that seem consistent with the US growth patterns in energy use and efficiency. Moreover, during the transition towards the balanced growth path this economy gains efficiency, since the capital to output ratio is growing and, therefore, so does the capital to energy ratio. Nevertheless, the share of energy is always constant and independent of the price, and energy use per unit of value added mirrors the behavior of the energy price, implications which are clearly counterfactual. Moreover, changes in the growth rate of ISTC have no effect on energy use; the ratio $\mathbf{v a} t / \mathbf{e}_{t}$ only depends on the energy price. This implies that incentives to innovate do not affect energy efficiency, which also contradicts the evidence found at the micro level, as shown by Steinbuks and Neuhoff (2010), or Knittel (2011). Hence, any theory that aims to replicate the fact that energy use is not that responsive to energy price changes has to depart with elastic energy demand.

\section{Putty-clay energy efficiency of vintage capital}

In this section we present our theory of investment in which, as the micro evidence suggests, energy efficiency is a feature of technology embodied in capital. We keep the market structure of the previous model economy. We refer to this model economy as the putty-clay vintage capital economy. 


\subsection{Technology and the physical environment}

In this new framework, capital is heterogeneous in two dimensions: vintage, denoted by $z$, and the energy required for the unit of capital to yield services, denoted by $e$. Plants are indexed by the class of capital installed, $(z, e)$. Productivity at the plant level is given by neutral technical progress, $A_{t}$, and the class of capital installed. Production at the plant level is

$$
y_{t}(z, e)=A_{t} \kappa_{t}(z, e)^{\alpha} h_{t}(z, e)^{1-\alpha}, z \leq t, e \in \mathbb{R}_{++} .
$$

Differently from the vintage structure, energy type $e$ is a continuous variable. In order to yield services the unit of capital needs to be combined with energy. The type $e$ determines the amount of energy needed to produce capital services. Formally,

$$
\kappa_{t}(z, e)=(1+\lambda)^{z(1-\phi)} e^{\phi}, z \leq t, e \in \mathbb{R}_{++}, \phi \in(0,1) .
$$

Hence, in this economy energy intensity is fixed ex-ante and becomes a feature of capital. The larger the value of $e$ the more energy intensive that unit of capital is. Energy intensity type $e$ and ISTC are meant to refer to different factors. We may think of type $e$ as engine power of a car, whereas $z$ refers to technological improvements that increase capital services which are not directed to saving energy. For instance, any improvement in the ergonomics of car seats, so that driving is less tiring, would be a change in the vintage of capital. ${ }^{3}$

As before, there is a technology that allows agents to transform final good of period $t$ into $(1+\theta)^{t}$ units of capital of vintage $t+1$. Now, however, producers must decide which energy intensity to build in the new units of capital. Specifically, we will denote as $x_{t}(e)$ the amount of final good invested in capital of vintage $t+1$ that will be operated with intensity type $e \in \mathbb{R}_{++}$at period $t+1$.

\subsection{Equilibrium properties}

Market arrangements are the same as in the previous economy.

\footnotetext{
${ }^{3}$ See Knittel (2011) for particular examples of embodied technical innovations.
} 


\subsubsection{The plant's problem}

The plant's problem is:

$$
\pi_{t}(z, e)=\max _{\substack{h_{t}(z, e) \geq 0, u_{t}(z) \in\{0,1\}}}\left[A_{t}\left((1+\lambda)^{z(1-\phi)} e^{\phi}\right)^{\alpha} h_{t}(z, e)^{1-\alpha}-w_{t} h_{t}(z, e)-p_{t}^{e} e\right] u_{t}(z, e)
$$

We have denoted the decision of the utilization of the plant as $u_{t}(z, e) \in\{0,1\}$. Thus, if the plant is not utilized it does not consume energy. This implies that a plant could be switched on and off depending on the energy price. Now, we characterize the optimal decision of utilization of the plant, which depends on plant's age and the energy price.

Proposition 1. Only plants that are not very intensive, $e \leq \bar{e}_{t}(z)$, are operated, $u_{t}(z, e)=1$, where $\bar{e}_{t}(z)$ is the maximum intensity type of plants operated in equilibrium.

Proof. If the plant is operated, the demand of labor is

$$
h_{t}(z, e)=\left(\frac{(1-\alpha) A_{t}}{w_{t}}\right)^{\frac{1}{\alpha}}(1+\lambda)^{z(1-\phi)} e^{\phi}
$$

Using this expression we rewrite profits (assuming that the plant is operated) as

$$
\alpha A_{t}\left(\frac{(1-\alpha) A_{t}}{w_{t}}\right)^{\frac{1-\alpha}{\alpha}}(1+\lambda)^{z(1-\phi)} e^{\phi}-p_{t}^{e} e \geq 0
$$

The cutoff value $\bar{e}_{t}(z)$ satisfies $\pi_{t}\left(z, \bar{e}_{t}(z)\right)=0$. Any class of capital $(z, e)$ where the energy requirement is above $\bar{e}_{t}(z)$ will not be used, $u_{t}(z, e)=0$, and it will yield $\pi_{t}(z, e)=0$.

\subsubsection{The choice of energy intensity of new capital}

The problem solved by the firms producing capital is

$$
\begin{array}{ll}
\pi_{t}^{x}=\max _{x_{t}(e) \geq 0} & \int_{0}^{\infty}\left[p_{t}(t+1, e)(1+\theta)^{t}-1\right] x_{t}(e) d e, \\
\text { s. t. } & x_{t}(e) \geq 0 .
\end{array}
$$

Thus, new capital is produced whenever $p_{t}(t+1, e) \geq(1+\theta)^{-t}$, whereas equilibrium dictates that $p_{t}(t+1, e) \leq(1+\theta)^{-t}$. Typically, there will be investment in equilibrium, thus, $p_{t}(t+1, e)=(1+\theta)^{-t}$ 
for any type $e \in \mathbb{R}_{+}$produced. Solving the household's problem we find that

$$
p_{t}(z, e)=\frac{1}{1+r_{t+1}}\left[(1-\varpi) p_{t+1}(z, e)+\pi_{t+1}(z, e)\right]+\psi_{t}(z, e)
$$

Expression (4.7) is the first order condition with respect to $k_{t+1}(z, e)$ in the household's problem. If $\psi_{t}(z, e)>0$, the household does not want to invest in class $(z, e)$. Working backwards, it must be the case that

$$
p_{t}(z, e)=\sum_{i=1}^{\infty} \frac{(1-\varpi)^{i-1}}{\prod_{j=1}^{i}\left(1+r_{t+j}\right)} \pi_{t+i}(z, e)
$$

Any new class of capital that is produced must satisfy

$$
p_{t}(t+1, e)=(1+\theta)^{-t}, e \in \mathbb{R}_{+}
$$

Now we turn to study the optimal choice of investment and the efficiency type of that investment. In order to do so, we need some previous results.

Lemma 1. Across all units of capital of the same vintage, $z \leq t$, profit is the highest for the type that satisfies

$$
e_{t}^{*}(z)=\phi^{\frac{1}{1-\phi}} \bar{e}_{t}(z)
$$

where $\bar{e}_{t}(z)$ is the type for which profit is zero at time $t$.

Proof. Profit at time $t$ is

$$
\pi_{t+i}(z, v)=\alpha A_{t}\left(\frac{(1-\alpha) A_{t}}{w_{t}}\right)^{\frac{1-\alpha}{\alpha}}(1+\lambda)^{z(1-\phi)} e^{\phi}-p_{t}^{e} e
$$

In Proposition 1 we defined $\bar{e}_{t}(z)$ as the efficiency type for which profit is zero. Thus, for any $e>\bar{e}_{t}(z)$ the plant is not utilized. Conditional on utilizing the plant, profit is maximized at the value $e_{t}^{*}(z)$, which satisfies $e_{t}^{*}(z)=\phi^{\frac{1}{1-\phi}} \bar{e}_{t}(z)$. Since $\phi<1$ we know that $e_{t}^{*}(z)<\bar{e}_{t}(z)$. Hence, profit of vintage $z$ has a unique maximum at $e_{t}^{*}(z)$.

We will focus our attention in economies where, once capital is left idle, it is never used back in 
production. This should be the case when fluctuations in prices are not too large. We will back to this issue in Section 4.4, where we study the balanced growth path of our model economy.

Proposition 2. Investment only takes place, at most, in one type of capital, $e_{t+1} \in \mathbb{R}_{+}$, which is the one that maximizes the present value of all future profits. Moreover, the optimal type $e_{t+1}$ is lower than the type that maximizes expected profit at period $t+1, e_{t+1}^{*}(t+1)$.

Proof. As we have seen, for any new class of capital to be produced it must be the case that the present value of all future profits must be equal to the cost of producing one unit of capital,

$$
(1+\theta)^{-t}=\sum_{i=1}^{\infty} \frac{(1-\varpi)^{i-1}}{\prod_{j=1}^{i}\left(1+r_{t+j}\right)} \pi_{t+i}(t+1, e)
$$

Expression (4.12) determines the set of intensity types $e \in \mathbb{R}_{+}$for which investment will be positive. Since the present value of all future profits is a weighted average of strictly concave functions that have a unique maximum, it follows that the average also have a unique maximum, denoted as $e_{t+1}$. Moreover, it must be the case that $e_{t+1}<e_{t+1}^{*}(t+1)$, otherwise it would be profitable to reduce $e$ to rise profits after period $t+1$.

Since agents have rational expectations, competition implies that households know that there is one intensity type that yields the highest present value of future profits. As a result, only one type has a positive price, which is the type that receives investment in equilibrium and, therefore, is produced. This proposition also implies that all units of capital of the same vintage have the same energy intensity.

\subsection{Aggregation}

We define a price for any class of capital in the following way:

Definition 1. Let the cost of one unit of capital of class $(z, e), z \leq t+1, e_{z} \in \mathbb{R}_{++}$, in units of gross output at time $t$ be defined as

$$
q_{t}\left(z, e_{z}\right) \equiv(1+\lambda)^{(z-t-1)(1-\phi)}\left(\frac{e_{z}}{e_{t+1}}\right)^{\phi}(1+\theta)^{-t}, z \leq t+1, e \in \mathbb{R}_{++}
$$


This price is the price of capital in units of gross output at time $t$. In Section 4.4 we will discuss the relationship of this price and the market price of capital. Notice that this price depends on energy intensity. This is consistent with Gordon (1990, 1996), who argued that not all changes in the relative price of capital goods are due to ISTC but also to changes in energy intensity (see Gordon, 1996, p. 262). It could be argued that we should find aggregate capital using market prices. We would do so if we could represent aggregate value added solely as a function of labor and capital, which we cannot do so because of the complementarity of capital and energy at the plant level. This complementarity implies that factor shares in aggregate value added depend on the distribution of capital across vintages. As a consequence, market prices of capital are not separable in time and class $(z, e)$ and, therefore, cannot be used to aggregate capital as in the putty-putty vintage capital economy shown in Section 3. Hence, we cannot write aggregate value added as a function of aggregate primary inputs. We can, however, find aggregate gross output since the share of labor in gross output is constant regardless of the capital vintage and energy intensity. ${ }^{4}$

\subsubsection{Aggregate capital}

The aggregate stock of capital in units of output is denoted as $\mathbf{k}_{t}$, as we did in the previous section. The difference with the putty-putty economy is that capital has a finite service life. This is due to the fact that the wage grows at the pace of neutral progress and ISTC whereas the energy cost is a fixed cost (and, possibly, the energy price grows over time). Thus, there must be a finite time at which profit is zero. A plant is never used after that period. We will characterize the service life of capital in Section 4.4 where we study the balanced growth path of this economy. Hence,

$$
\mathbf{k}_{t}^{a}=\sum_{z=\underline{z}_{t}}^{t} q_{t-1}\left(z, e_{z}\right) k_{t}\left(z, e_{z}\right)
$$

That is, we follow National Accounts and define the aggregate stock as the sum of economically active capital. Thus, $\underline{z}_{t}$ is the last vintage used in production. It will be helpful to define $\mathbf{k}_{t}$, the total stock of capital in the economy,

$$
\mathbf{k}_{t}=\sum_{z=\infty}^{t} q_{t-1}\left(z, e_{z}\right) k_{t}\left(z, e_{z}\right)
$$

\footnotetext{
${ }^{4}$ See Sato (1976) for a more detailed discussion on the issue of aggregation.
} 
We do this because the depreciation rate of active capital, $\mathbf{k}_{t}^{a}$, is not geometric due to its finite service life. Taking into account that investment takes place only in one class of capital, we can write total capital as

$$
\mathbf{k}_{t}=\sum_{z=-\infty}^{t}(1-\varpi)^{t-z}(1+\lambda)^{(z-t)(1-\phi)}\left(\frac{e_{z}}{e_{t}}\right)^{\phi}(1+\theta)^{-t+1}(1+\theta)^{z-1} x_{z-1}
$$

which can be written recursively as

$$
\mathbf{k}_{t}=x_{t-1}+\left(1-\delta_{t}\right) \mathbf{k}_{t-1}
$$

The factor $\delta_{t}$ is the depreciation rate of the total stock of capital $\mathbf{k}_{t}$ between period $t-1$ and $t$. Its expression is

$$
\delta_{t}=1-\frac{1-\varpi}{(1+\lambda)^{1-\phi}(1+\theta)}\left(\frac{e_{t-1}}{e_{t}}\right)^{\phi} .
$$

The depreciation of the total stock depends not only on physical decay but also on economic obsolescence due to ISTC and changes in energy intensity. Since we are assuming that energy intensity responds to changes in energy prices, this implies that depreciation of capital is endogenous, too. The total stock of capital $\mathbf{k}_{t}$ and the economically active stock $\mathbf{k}_{t}^{a}$ are related in the following way:

$$
\mathbf{k}_{t}=\mathbf{k}_{t}^{a}+\left(1-\Delta_{t}\right) \mathbf{k}_{\underline{z}_{t}-1}
$$

The factor $\left(1-\Delta_{t}\right)$ is equal to the factor $\prod_{j=\underline{z}_{t}}^{t}\left(1-\delta_{j}\right)$ and it measures the remaining value of the stock of class $\left(j, e_{j}\right)$ (in units of gross output) once physical depreciation and obsolescence are taken into account. The stock of active capital adjusted by quality is

$$
\kappa_{t}^{a}=\sum_{z=\underline{z}_{t}}^{t} \frac{q_{t-1}\left(z, e_{z}\right)}{q_{t-1}(0,1)} k_{t}\left(z, e_{z}\right)=(1+\lambda)^{t(1-\phi)} e_{t}^{\phi}(1+\theta)^{t-1} \mathbf{k}_{t}^{a}
$$

and correspondingly, $\kappa_{t}$ is the total stock of capital adjusted by quality, which satisfies $\kappa_{t}=(1+$ $\lambda)^{t(1-\phi)} e_{t}^{\phi}(1+\theta)^{t-1} \mathbf{k}_{t}$. The cost of quality-adjusted capital is

$$
q_{t}^{\kappa}=(1+\lambda)^{-(t+1)(1-\phi)} e_{t+1}^{-\phi}(1+\theta)^{-t} .
$$


Consistently with Gordon (1990) and Cummins and Violante (2002), this price falls when ISTC rises, as measured by $(1+\lambda)^{-(t+1)(1-\phi)}(1+\theta)^{-t}$, but it also falls with energy intensity. Thus, when agents invest in lowering energy intensity of new capital, the relative price of new capital rises, as it was suggested by Gordon (1996). Thus, our theory says that we cannot attribute all changes in the relative price of investment to ISTC but also to changes in energy intensity.

\subsubsection{Aggregate output}

The amount of output produced and labor employed at the plant level are proportional to the services yielded by the unit of capital installed in the plant:

$$
\frac{h_{t+i}\left(z, e_{z}\right)}{h_{t+i}\left(t, e_{t}\right)}=\frac{y_{t+i}\left(z, e_{z}\right)}{y_{t+i}\left(t, e_{t}\right)}=(1+\lambda)^{(z-t)(1-\phi)}\left(\frac{e_{z}}{e_{t}}\right)^{\phi}, \text { for all } i \geq 0
$$

Hence, labor is withdrawn gradually from older plants and placed in newer plants. Notice, though, that more efficient plants (those whose energy intensity, $e$, is lower) demand less labor than less efficient plants. Hence, the pattern of reallocation of labor across vintages is not clear. Aggregate production, using $(4.22)$, can be written as

$$
\mathbf{y}_{t}=\sum_{z=\underline{z}_{t}}^{t} y_{t}\left(t, e_{t}\right)(1+\lambda)^{(z-t)(1-\phi)}\left(\frac{e_{z}}{e_{t}}\right)^{\phi} k_{t}\left(z, e_{z}\right)
$$

where $\underline{z}_{t}$ is the oldest vintage used in production. The expression for gross output simplifies to

$$
\mathbf{y}_{t}=y_{t}\left(t, e_{t}\right) \sum_{z=\underline{z}_{t}}^{t}(1+\lambda)^{(z-t)(1-\phi)}\left(\frac{e_{z}}{e_{t}}\right)^{\phi} k_{t}\left(z, e_{z}\right)=y_{t}\left(t, e_{t}\right)(1+\theta)^{t-1} \mathbf{k}_{t}^{a}
$$

Aggregate labor is

$$
\mathbf{h}_{t}=\sum_{z=\underline{z}_{t}}^{t} h_{t}\left(t, e_{t}\right)(1+\lambda)^{(z-t)(1-\phi)}\left(\frac{e_{z}}{e_{t}}\right)^{\phi} k_{t}\left(z, e_{z}\right)
$$

After some manipulations, aggregate gross output can be written as

$$
\mathbf{y}_{t}=A_{t}\left((1+\lambda)^{t(1-\phi)} e_{t}^{\phi}(1+\theta)^{t-1}\right)^{\alpha}\left(\mathbf{k}_{t}-\left(1-\Delta_{t}\right) \mathbf{k}_{\underline{z}_{t}-1}\right)^{\alpha} h_{t}^{1-\alpha}
$$


Energy consumption of the stock of active capital at time time is denoted as $\mathbf{e}_{t}^{a}$ and is equal to the difference $\mathbf{e}_{t}-(1-\varpi)^{t-\underline{z}_{t}+1} \mathbf{e}_{\underline{z}_{t}-1}$, where

$$
\mathbf{e}_{t}=\sum_{z=-\infty}^{t} k_{t}\left(z, e_{z}\right) e_{z}
$$

whose law of motion can be written as

$$
\mathbf{e}_{t+1}=e_{t+1}(1+\theta)^{t} x_{t}+(1-\varpi) \mathbf{e}_{t}
$$

The evolution of the aggregates in our economy is described by the expression for gross output, (4.26), the feasibility condition,

$$
c_{t}+x_{t}=\mathbf{y}_{t}-p_{t}^{e}\left(\mathbf{e}_{t}-(1-\varpi)^{t-\underline{z}_{t}+1} \mathbf{e}_{\underline{z}_{t}-1}\right)
$$

the laws of motion of capital, (4.17), the energy requirement, (4.28), and the expression for profits that pins down the oldest vintage, $\underline{z}_{t}$, for which profit is non negative,

$$
\alpha \frac{\mathbf{y}_{t}}{\mathbf{k}_{t}^{a}}(1+\lambda)^{\left(\underline{z}_{t}-t\right)(1-\phi)}\left(\frac{e_{\underline{z}_{t}}}{e_{t}}\right)^{\phi}(1+\theta)^{-t+1}-p_{t}^{e} e_{\underline{z}_{t}} \geq 0 .
$$

The equilibrium allocation can be found maximizing the utility function subject to (4.26),(4.29), (4.17), (4.28), and (4.30), but the dimensionality of the problem is very large. However, we can already learn some things. For instance, value added per unit of energy use differs across vintages,

$$
\frac{y_{t}(z)-p_{t}^{e} e_{z}}{e_{z}}=A_{t}\left(\frac{(1-\alpha) A_{t}}{w_{t}}\right)^{\frac{1-\alpha}{\alpha}}(1+\lambda)^{z(1-\phi)} e_{z}^{\phi-1}-p_{t}^{e}
$$

Older and more energy intensive vintages yield less value added per unit of energy used than newer ones. The evolution of aggregate value added per unit of energy depends on the composition of capital; that is, on the amount invested in each class of capital and the choice of intensity type. Likewise, efficiency, as measured by the capital (in units of gross output) to energy ratio for any vintage $z \leq t$ is

$$
\frac{q_{t-1}(z)}{e_{z}}=\frac{(1+\lambda)^{(z-t)(1-\phi)}\left(\frac{e_{z}}{e_{t}}\right)^{\phi}(1+\theta)^{-t+1}}{e_{z}}
$$


which also varies across vintages. In particular, efficiency is lower for older, more intensive vintages. Thus, the response of the aggregate ratios to changes in the energy price will depend on the response of investment, the growth rate of ISTC, the depreciation rate of capital and the length of its service life.

The characterization of the equilibrium allocation also shows the key trade-offs that this economy faces regarding technical innovations. For instance, investing in energy efficiency (i.e., lower $e_{t+1}$ ) lowers the energy bill but it also lowers services of capital and, therefore, gross output. Thus, the investment decision will depend on the evolution of the energy price and the nature of ISTC; i.e., whether ISTC innovations increase the quality of capital (the intensive margin) or reduce the cost of producing capital, (the extensive margin). In the first case, an acceleration in the growth rate of the intensive margin of ISTC, $\lambda$, amounts to obtaining more services out of one unit of capital regardless of its energy intensity. Hence, innovations at the intensive margin of ISTC could be thought of as energy saving innovations. An acceleration in the growth rate of the extensive margin of ISTC, $\theta$, reduces the cost of investment. Since capital needs of energy to yield services, innovations at the extensive margin of ISTC demand energy. Since energy efficiency is endogenous in this economy, its evolution over time will depend on the interaction of ISTC and the energy price. To study more deeply these implications why we turn to characterize the balanced growth path.

\subsection{The balanced growth path}

To characterize the balanced growth path we need to set the growth rate of neutral progress and the energy price.

Assumption 1. We assume that neutral progress and the energy price grow at a constant rate: $A_{t}=$ $A\left(1+\gamma_{a}\right)^{t}$, and $p_{t}^{e}=p^{e}\left(1+\gamma_{p}\right)^{t}$, with $\gamma_{a}>\gamma_{p}$.

\subsubsection{Characterizing the balanced growth path}

The notion of balanced growth path requires the lifetime of capital to be constant. Given this conjecture, we obtain the growth rate of all aggregates at the balanced growth path and show that our conjecture is, indeed, correct.

Proposition 3. At the balanced growth path, the lifetime of capital is constant, $T=t-\underline{z}_{t}+1$, energy 
intensity of new capital falls over time at the rate of the extensive margin of ISTC and the growth rate of the energy price,

$$
e_{t+1}=\widehat{e}\left[\left(1+\gamma_{p}\right)(1+\theta)\right]^{-t}
$$

the price of capital adjusted by quality falls at a rate given by the two margins of ISTC, and rises with the growth rate of the energy price,

$$
\frac{q_{t}^{\kappa}}{q_{t+1}^{\kappa}}=[(1+\lambda)(1+\theta)]^{1-\phi}\left(1+\gamma_{p}\right)^{-\phi}
$$

gross output, $\mathbf{y}_{t}$ and capital, $\mathbf{k}_{t}$, grow at the rate $g$ that satisfies

$$
(1+g)=\left(1+\gamma_{a}\right)^{\frac{1}{1-\alpha}}[(1+\lambda)(1+\theta)]^{\frac{\alpha(1-\phi)}{1-\alpha}}\left(1+\gamma_{p}\right)^{\frac{-\alpha \phi}{1-\alpha}}
$$

the amount of energy, $\mathbf{e}_{t}$, grows at the rate $g_{e}$ that satisfies:

$$
\left(1+g_{e}\right)=(1+g) /\left(1+\gamma_{p}\right)
$$

the depreciation rate of capital, $\delta_{t}$, is constant and depends on the growth rate of ISTC and the growth rate of the energy price,

$$
\delta=1-\frac{1-\varpi}{[(1+\lambda)(1+\theta)]^{1-\phi}\left(1+\gamma_{p}\right)^{-\phi}}
$$

the stock of active capital, $\mathbf{k}_{t}^{a}$, is the fraction $u$ of the total stock utilized in production, where $u$ satisfies

$$
u \equiv \frac{\mathbf{k}_{t}-(1-\delta)^{T} \mathbf{k}_{t-T}}{\mathbf{k}_{t}}=1-\left(\frac{1-\delta}{1+g}\right)^{T}
$$

the amount of energy consumed, $\mathbf{e}_{t}^{a}$, is the fraction $u^{e}$ of the energy requirement of the total stock of capital $\mathbf{k}_{t}$, where $u^{e}$ satisfies:

$$
u^{e} \equiv \frac{\mathbf{e}_{t}-(1-\varpi)^{T} \mathbf{e}_{t-T}}{\mathbf{e}_{t}}=1-\left(\frac{(1-\varpi)\left(1+\gamma_{p}\right)}{1+g}\right)^{T}
$$


The first result is implied by the fact that the energy share should be constant at a balanced growth path. Thus, the energy bill, $p_{t}^{e} \mathbf{e}_{t}^{a}$, should grow at the same rate that gross output. As a consequence, the type $e_{t}$, that measures energy intensity of new capital, falls at a rate given by the extensive margin of ISTC, $\theta$, and the trend growth in the energy price. Thus, new investment is placed in less intensive types to compensate the fact that more capital requires more energy. The growth rate of quality-adjusted capital and gross output depend on neutral progress and ISTC. Finally, the depreciation rate of capital (measured in units of gross output), $\delta$, includes economic obsolescence. Thus, the larger the rate of ISTC, the larger the depreciation rate of capital. However, quality adjusted capital only depreciates by physical decay, $\varpi$. Finally, the size of the stock of active capital is endogenous and depends on the depreciation rate and the lifetime of capital, which depend, in their turn, on the growth rate of ISTC.

Along the balanced growth path the growth rate of the optimal intensity type, $e_{t+1}$, only depends on the growth rate of the extensive margin of ISTC. It follows that in absence of the extensive margin of ISTC, energy efficiency of new capital goods is totally determined by the behavior of the energy price, which seems to be at odds with the data, as shown by Steinbuks and Neuhoff (2010), or Knittel (2011). The energy price, though, determines the level, $\widehat{e}$. To see this, we are going to characterize the optimal level of output to (quality adjusted) capital ratio, the efficiency type level, $\widehat{e}$, and the lifetime of capital. To do so we need to maximize (3.1) subject to (4.26),(4.29), (4.17), (4.28), and (4.30), particularized at the balanced growth path.

Proposition 4. Along the balanced growth path, the detrended intensity type, $\widehat{e}$, output to capital ratio, $\widehat{\mathbf{y}} /(u \widehat{\mathbf{k}})$, and the lifetime of capital, $T$, satisfy the following conditions:

1. The output to capital ratio, $\widehat{\mathbf{y}} / \widehat{\mathbf{k}}$ equates the (detrended) price of investment to the present value of future profits:

$$
1=\sum_{i=1}^{T} \frac{(1-\varpi)^{i-1}}{(1+r)^{i}}\left[\frac{\alpha \widehat{\mathbf{y}}}{u \widehat{\mathbf{k}}}\left[[(1+\lambda)(1+\theta)]^{(1-\phi)}\left(1+\gamma_{p}\right)^{-\phi}\right]^{1-i}-\left(1+\gamma_{p}\right)^{i} p^{e} \widehat{e}\right]
$$

where the interest rate satisfies $\beta(1+r)=(1+g)^{\sigma}$ and $g$ is the growth rate of gross output, $\sigma$ is the intertemporal elasticity of substitution in consumption, and the utilization rate of capital, $u$, is given by expression (4.38). 
2. The detrended efficiency type $\widehat{e}$ is the unique type that maximizes the return to investment,

$$
0=\sum_{i=1}^{T} \frac{(1-\varpi)^{i-1}}{(1+r)^{i}}\left[\frac{\phi \alpha \widehat{\mathbf{y}}}{u \widehat{\mathbf{k}}}\left[[(1+\lambda)(1+\theta)]^{(1-\phi)}\left(1+\gamma_{p}\right)^{-\phi}\right]^{1-i}-\left(1+\gamma_{p}\right)^{i} p^{e} \widehat{e}\right]
$$

3. The lifetime of capital, $T$, is the last period in which profit is non negative,

$$
\begin{aligned}
& \frac{\alpha \widehat{\mathbf{y}}}{u \widehat{\mathbf{k}}}\left[[(1+\lambda)(1+\theta)]^{(1-\phi)}\left(1+\gamma_{p}\right)^{-\phi}\right]^{1-T}-\left(1+\gamma_{p}\right)^{T} p^{e} \widehat{e} \geq 0, \\
& \frac{\alpha \widehat{\mathbf{y}}}{u \widehat{\mathbf{k}}}\left[[(1+\lambda)(1+\theta)]^{(1-\phi)}\left(1+\gamma_{p}\right)^{-\phi}\right]^{T}-\left(1+\gamma_{p}\right)^{T+1} p^{e} \widehat{e}<0 .
\end{aligned}
$$

Proof. We have maximized (3.1) subject to (4.26),(4.29), (4.17), (4.28), and (4.30), particularized at the balanced growth path and detrended all variables according to Proposition 3. Expression (4.40) is the first order condition of the constrained maximization problem with respect to $x$, investment. It also coincides with (4.12), which is the first order condition with respect to investment in the household's maximization problem in the decentralized economy. Expression (4.41) is the f.o.c. with respect to $\widehat{e}$. This expression follows from maximizing with respect to $e \in \mathbb{R}_{+}$expression (4.12), the present value of future profits of one unit of capital of class $(t+1, e)$. Expression (4.41) says that energy expenditures associated to the new class of capital must be the fraction $\phi \alpha$ of the present value of gross output along its service life. Finally, expressions (4.42) and (4.43) are the terminal conditions that determine the service life of capital, $T$, at the balanced growth path.

The previous three equations characterize the detrended aggregates along the balanced path. For instance, combining (4.41) and (4.42) we can characterize the lifetime of capital, $T$, which can be approximated by the continuous variable $\widetilde{T}$ that satisfies

$$
\left[(1+\lambda)(1+\theta)\left(1+\gamma_{p}\right)\right]^{(1-\phi) \widetilde{T}}=\frac{1}{\phi} \frac{r+\delta}{r+\widetilde{\varpi}} \frac{(1+r)^{\widetilde{T}-1}-(1-\widetilde{\varpi})^{\widetilde{T}-1}}{(1+r)^{\widetilde{T}-1}-(1-\delta)^{\widetilde{T}-1}},
$$

where $\widetilde{\varpi}$ satisfies $1-\widetilde{\varpi}=(1-\varpi)\left(1+\gamma_{p}\right)$. The service life of capital is the integer part of $\widetilde{T}$, $T=\lfloor\widetilde{T}\rfloor$. The upper bound for capital's service life $\widetilde{T}$ can approximated by

$$
\widetilde{T} \approx \frac{\log (r+\delta)-\log (r+\widetilde{\varpi})-\log (\phi)}{(1-\phi)\left[\log (1+\lambda)+\log (1+\theta)+\log \left(1+\gamma_{p}\right)\right]}
$$

Thus, the service life of capital does not depend on the level of the energy price; it rather depends 
on the pace of growth of the economy. In particular, it depends on the difference between physical decay, $\varpi$, the growth rate of the energy price and economic obsolescence, $\delta$. Physical decay, $\varpi$, also measures how energy intensity falls in the economy, since the energy requirement is not related to productivity of capital, given by the change in ISTC. The second rate, $\delta$, measures the contribution of capital in production. Since $\delta>\varpi$, it implies that the productive contribution of capital falls faster than its energy requirement. As a result, the service life of capital is finite. Combining equations (4.40) and (4.41) we can see that energy price, however, determines the detrended level of intensity type,

$$
1+r=\frac{1-\phi}{\phi} p^{e} \widehat{e} \sum_{i=1}^{T}\left(\frac{1-\varpi}{1+r}\right)^{i-1}\left(1+\gamma_{p}\right)^{i}
$$

Notice also that the lower $T$, the larger is $\widehat{e}$. The larger the growth rate of ITSC, due to either the intensive, $\lambda$, or the extensive margin, $\theta$, the shorter the lifetime of capita, $T$, due to obsolescence. It follows that the higher growth rate of ISTC the higher the detrended level of energy requirement $\widehat{e}$. Thus, intensive and extensive margin of ISTC have different effects. Changes in the growth rate of the intensive margin of ISTC only affect the level of the energy requirement, but not its growth rate. Changes in the extensive margin of ISTC affect both the level and the growth rate. Hence, we can infer how the two margins of ISTC affect energy efficiency in the long run.

Corollary 1. Larger ISTC growth rate, due to either the intensive, $\lambda$, or the extensive margin, $\theta$, implies a shorter lifetime of capital, $T$, and a larger level of energy use per unit of capital, $\widehat{e}$.

This Corollary says that higher ISTC growth may produce a rebound effect, as measured by the level of the energy requirement, $e_{t+1}$. The final effect will depend on the behavior of investment. In order to asses the interactions of ISTC and energy prices in determining the long run level of energy use and energy efficiency, as well as their dynamics, we need to use quantitative tools. Before turning to that issue we want to discuss a bit the issue about the market value of of capital.

\subsubsection{The market value of capital}

We have aggregated capital using the price $q_{t}(z, e)$, shown in expression (1). This is the price of capital in units of gross output. It is not the market price of capital (in units of value added), $p_{t}(z, e)$, which is given by the present value of all future profits, net of energy expenditures, as 
shown in expression (4.12). In our version of Solow (1960), both prices coincide since, in that case, energy is not a feature of technology. By using the price of capital in units of gross output, $q_{t}(z, e)$, we are able to represent the evolution of the total stock recursively, as shown in expression (4.17). This is the advantage of our representation. Nevertheless, we should bear in mind that the market value of the total economically active stock is

$$
\mathbf{k}_{t}^{a}=\sum_{z=\underline{z}_{t}}^{t} p_{t-1}\left(z, e_{z}\right) k_{t}\left(z, e_{z}\right)
$$

The market price of capital of class $\left(z, e_{z}\right)$ has a complicated expression. Nevertheless, at the balanced growth path, using Propositions 3 and 4, it can be written as

$$
p_{t}\left(z, e_{z}\right)=q_{t}\left(z, e_{z}\right) \frac{\Upsilon_{1}(t, z)}{1-\phi}-(1+\theta)^{-(z-1)}\left(1+\gamma_{p}\right)^{t-z+1} \frac{\Upsilon_{2}(t, z) \phi}{1-\phi}
$$

where factors $\Upsilon_{1}(t, z)$ and $\Upsilon_{2}(t, z)$ are

$$
\Upsilon_{1}(t, z)=\frac{1-\left(\frac{1-\delta}{1+r}\right)^{T-t+z-2}}{1-\left(\frac{1-\delta}{1+r}\right)^{T-1}}, \text { and } \Upsilon_{2}(t, z)=\frac{1-\left(\frac{1-\widetilde{\varpi}}{1+r}\right)^{T-t+z-2}}{1-\left(\frac{1-\widetilde{\varpi}}{1+r}\right)^{T-1}} \text {, }
$$

for all $z \leq t+1$, and $T-(t+1-z) \geq 1$. Notice that this expression collapses to $(1+\theta)^{-t}$ for the latest vintage, $t+1$. The divergence between the market price and the value in units of gross value added increases with the age of capital. Thus, the stock of capital in units of gross output is larger than the value of capital in units of value added.

\section{Energy, ISTC, and long term growth}

In this section we conduct some exercises to quantify the macroeconomics implications of modeling energy efficiency as a feature of technology embodied in capital, as the micro evidence suggests.

\subsection{Calibration}

We use the data collected for the US economy described in Section 2. Appendix A describes in detail the sources and the processing of the data. In Section 2 we have already described the construction 
of the composite energy, $E$, and its relative price. Table 3 shows the targets used in our calibration procedure. We have calibrated three different economies. For the time being, we are going to focus on the putty-putty and the putty-clay economies, the ones studied in the previous sections. We calibrate both economies to two different scenarios. In Scenario 1 we assume that the energy price has no trend growth. Thus, if we want to interpret the data under this assumption we have to assume that changes in the energy price are all due to cyclical fluctuations. In Scenario 2 the energy price has a positive trend in growth. We set it equal to the mean growth rate of the ratio of aggregate value added to energy use, $V A / E$, which was 1.54 percent for the period 1960-2014. Clearly, even in this scenario we have to assume that there are significant fluctuations in the price to rationalize the data.

\subsubsection{The putty-putty vintage economy}

Let us start describing the calibration of the putty-putty economy. In this case, the calibration is almost invariant with respect to the energy price scenario. The only parameter affected is the growth rate of neutral progress, $\gamma_{a}$, since changes in the energy price are tantamount to changes in neutral progress in the putty-putty economy. In both scenarios we proceed by setting $\alpha$ to match the share of labor in aggregate value added, the discount factor $\beta$ to match the observed capital to value added ratio and $\phi$ to match the share of energy, which is $\alpha \phi /(1-\alpha \phi)$ in this economy. The (inverse of) the growth rate of the quality-adjusted relative price of investment goods is equal to $(1+\lambda)(1+\theta)$, which is the composite growth factor of ISTC. Thus, we set $(1+\lambda)(1+\theta)=1.0258$ in both energy price scenarios. At the balanced growth path the growth rate of value added is equal to

$$
1+g=\left[\left(1+\gamma_{a}\right)\left(1+\gamma_{p}\right)^{-\alpha \phi}\right]^{\frac{1}{1-\alpha}}\left(\frac{q_{t-1}^{\kappa}}{q_{t}^{\kappa}}\right)^{\frac{\alpha(1-\phi)}{1-\alpha}}
$$

Thus, if the energy price has a trend we end up with a lower contribution of neutral progress, and viceversa. Summarizing, according to this theory movements in the relative price of capital are a good proxy for ISTC and changes in the energy price are tantamount to changes in neutral progress. The rate of physical decay of capital is $\varpi$, which is set to match the observed investment rate, but economic obsolescence is given by $\delta$, which satisfies $\delta=1-(1-\varpi) /[(1+\lambda)(1+\theta)]$. This depreciation rate is $\delta=0.0928$. 


\subsubsection{The putty-clay vintage economy}

Calibrating the putty-clay economy is a bit more convoluted than the putty-putty economy because of the service life of capital is finite. This implies that the average productivity of active capital is endogenous and affects the capital to value added ratio, as well as the energy share. This is why the calibration of this economy changes slightly between scenarios; most noticeably, the parameter $\phi$ (going from 0.0949 in Scenario 1 to 0.0902 in Scenario 2) which is pinned down to match the energy share in value added and, less significantly, the discount factor. The most important difference across scenarios, though, is the measurement of ISTC versus neutral progress. In this economy, the growth rate of value added at the balanced growth path is equal to

$$
1+g=\left(1+\gamma_{a}\right)^{\frac{1}{1-\alpha}}\left(\frac{q_{t-1}^{\kappa}}{q_{t}^{\kappa}}\right)^{\frac{\alpha}{1-\alpha}}
$$

Energy efficiency is a feature of capital, and therefore, it affects the relative price of capital. Here, as shown in equation (4.34), the growth rate of the relative price of capital depends not only on ISTC but also on the trend growth of the energy price. Hence, measured ISTC is different in each scenario, whereas measured neutral progress is the same. We should emphasize that not only trend movements in energy prices affect the measurement of ISTC. If there were any transitory movement

in the energy price it would affect the optimal choice of energy efficiency, $\widehat{e}$, what would affect the service life of capital.

The more noticeable differences between the calibration of the putty-putty and the putty-clay economies are the value of the parameter $\phi$, which governs the energy share in aggregate value added, and the measurement of ISTC. The relative price of capital does not depend on the behavior of the energy price in the putty-putty economy. Thus, $(1+\lambda)(1+\theta)=1.0258$ in both Scenarios. In the putty-clay economy, however, the estimate of the ISTC growth goes from 1.0286 to 1.0311. Neutral progress behaves in the opposite way. In the putty-putty economy, the estimate of neutral progress goes from -0.0030 in Scenario 1 to -0.0024 in Scenario 2. In the putty-clay economy, however, the measurement of neutral progress is not affected by the behavior of the energy price. Summarizing, the decomposition of technical progress in neutral and investment specific technical change is affected by the theory of energy use considered.

Finally, in Figure 3 we show the bias in which we incur by using prices in units of gross output, $q_{t}(z, e)$, to aggregate capital instead of market prices, $p_{t}(z, e)$, for all $z \leq t$ and $e \in \mathbb{R}_{++}$. Figure 
3(a) shows the ratio $p_{t}\left(z, e_{z}\right) / q_{t}\left(z, e_{z}\right)$ for all active vintages in the two possible Scenarios. The bias rises substantially with the age of the vintage. In Figure 3(b) we show the bias weighted by the existing amount of capital of vintage $z$ at time $t$, which is $(1-\varpi)^{t-z}$. Thus, the maximum weighted bias in the value of capital is about 2 percent. Hence, we conclude that our measure of capital (which is consistent with the National Accounts procedure) is a good proxy for the market value of the stock of capital.

\subsection{Long term consequences of changes in ISTC}

Table 4 summarizes the long run effects of changes in ISTC and energy prices in the four statistics considered in Section 2: the amount of value added per unit of energy used, $V A / E$, the energy share in aggregate value added, $p E / V A$, the ratio of capital to energy use, $K / E$, and the standard capital to aggregate value added ratio, $K / V A$. We start by showing the effects of a permanent increase in the growth rate of ISTC of 50 percent. ${ }^{5}$ We have denoted as $(1+\lambda)(1+\theta)$ the ISTC factor. Thus, we do not specify, by now, the nature (i.e., intensive or extensive margin) of the change in ISTC.

The first row of Table 4 shows the effect of an increase in the growth rate of ISTC in the puttyputty economy. As we can see, its effect is limited to a reduction in the capital to value added ratio. This is a standard result in a neoclassical growth model economy: whenever the growth rate of technical change increases, obsolescence of capital rises, investment rises as a share of value added, and the value of the stock in units of output decreases. Value added per unit of energy use, however, is not affected at all since it only depends on the energy price. As a result, the ratio $K / E$ decreases and the economy, in the aggregate, becomes less energy efficient: value added and energy both augment in the same proportion per unit of capital. The energy share, then, is unaffected, too. These results are in line with the theory results already obtained in Section 3.4.

Let us turn now to the putty-clay economy in Scenario 1, where the energy price has no trend. Notice that in this economy the amount of value added per unit of energy used, $V A / E$, and the capital to energy ratio, $K / E$, are constant at the balanced growth path. That is, this economy cannot reproduce the fact that both the value added to energy ratio, $V A / E$, and the capital to

\footnotetext{
${ }^{5}$ Given our calibration, the response to a 5 percent shock in ISTC growth (less than a 1 percent shock of the growth factor), is of the order of magnitude of the response to a 1 percent shock in the energy price (a shock which quantitatively we better know: a $1 \%$ shock to $p^{e}$ is very small; The oil price shocks of the 70 s and the $2005-2008$ oil price boom were shocks of about a $20 \%$ size). Thus, next we implement a $10 \%$ shock in the oil price and a $50 \%$ shock to ISTC growth.
} 
energy ratio, $K / E$, are growing over time. A permanent 50 percent increase in the growth rate of ISTC produces a permanent fall in the ratios $V A / E$ and $K / E$ (1.19 and 13.67 percent, respectively. The energy share rises a bit, 1.20 percent. That is, the economy uses energy more intensively and less efficiently in the aggregate. The effect is the same regardless of the nature (intensive or extensive margin) of the innovation in ISTC. Hence, a permanent increase in the growth rate of ISTC produces a rebound effect in energy use in Scenario 1, in line with the cross-section evidence in Section 2 under a common trend scenario across OECD countries -cf. regression (6).

To understand why this is the case we analyze the effect of each margin of ISTC separately. Assume that all technical change is due to the intensive margin, quality improvements, so that $\lambda$ increases permanently, whereas $\theta$ remains constant. This implies that new capital yields more services regardless of its energy efficiency. If the choice of efficiency of new capital, $e_{t+1}$, remained the same, as well as the service life of capital, the amount of value added per unit of energy used should increase when $\lambda$ increases (instead of falling). Thus, other things offset the direct impact of the increased productivity of capital. First, economic obsolescence rises: the depreciation rate rises from $\delta=0.0928$ to $\delta=0.1040$ (see Table 5). The service life of capital is reduced from 100 periods to 68 and investment rises as a fraction of value added. Since service life of capital is shorter, the detrended efficiency level of new capital is reduced: $\widehat{e}$ rises from 0.0133 to 0.0144 . We should be careful, though, because the efficiency of new capital, $e_{t+1}$ still falls at the rate $(1+\theta)$. Let us turn to consider the other extreme case: there is a permanent change in $\theta$ whereas $\lambda$ remains constant. In this case, new capital is so much cheaper in units of consumption that it can lose efficiency level, $\widehat{e}$, but notice that the efficiency of new capital will rise faster, since $e_{t+1}$ will fall at a faster rate, since $e_{t+1}=\widehat{e}\left[(1+\theta)\left(1+\gamma_{p}\right)\right]^{-t}$. Summarizing, permanently higher ISTC augments energy use and reduces aggregate efficiency if agents know that the energy price does not move.

Now we move to discuss the effect of a permanent change in ISTC in the putty-clay vintage economy in Scenario 2, where the energy price grows at a constant rate (see row 3 in Table 4 and row 2 in bottom panel of Table 5). In this economy both the value added to energy used ratio, $V A / E$, and the capital to energy ratio, $K / E$, have a positive trend. Both ratios grow at the rate of $\gamma_{p}$, the growth rate of the energy price. The change of the main aggregate statistics is shown in the third row of Table 4. The effect is the opposite found in Scenario 1. That is, there is no rebound effect, since the (detrended) amount of value added per unit of energy used, $V A / E$, increases a bit, whereas the effect on aggregate energy efficiency, $K / E$, has the same sign that in Scenario 1 and 
about the same magnitude. The main difference is due to the fact that the service life of capital does not fall as much as in Scenario 1 (it goes from 67 years to 51 years, whereas in Scenario 1 it falls from 100 to 68 years) and investment rises a bit more as a fraction of value added. Thus, the direct effect of rising the productivity of capital prevails and value added per unit of energy used increases.

Hence, in the putty-clay economy a permanent change in ISTC have opposite effects in the behavior of the aggregate value added to energy used ratio, $V A / E$, depending on the behavior of energy prices. There is rebound effect in the case in which agents know that energy prices do not change. If the energy price is permanently rising (or its change has persistence) agents will not reduce energy efficiency. Notice, though, that the detrended level of energy intensity of investment, $\widehat{e}$, rises. That is, efficiency of new investment falls on impact although in the long run it will rise at a higher pace given by the higher growth tate of ISTC in both Scenarios. Thus, just be looking at the efficiency built in new capital we cannot assess whether there is rebound effect at the aggregate level. This result may help to understand why the evidence about the rebound effect seems so mixed, (see, for instance, Gillingham et al., 2016).

To investigate further the effect of rise of ISTC we report in Figure 4 the distribution of labor across vintages. Age 0 refers to vintage $t$ used at time $t$, whereas age 25 refers to vintage $25+t$. Figure 4 shows the amount of labor allocated to vintages of age from 0 to 25 as a percentage of total labor, which is normalized to one. In both economies the allocation is very similar for age younger than 65. We should take into account that, even though both economies differ in the service life of capital, the fact that there is physical decay implies that the amount that remains of old capital is very small. This is why we only report the labor allocation across vintages for the putty-clay economy and only for vintages younger than 30 years old. In the benchmark economy, the newest vintage is allocated about 10 percent of the aggregate labor. This implies that every period 10 percent of the labor force is reallocated from older to the latest vintage. This fraction of the labor force increases to more than 12 percent when there is a permanent increase of 50 percent in the growth rate of ISTC. Thus, old vintages reduce employment in 2 more percentage points. Thus, we find a significant effect in labor reallocation due to changes in ISTC. 


\subsection{Long term consequences of changes in the energy price}

Now we want to consider the long run effect of a permanent increase in the level of the energy price. It is very interesting to note that all economies behave in the same way in the long run. An increase in 10 percent in the price produces a corresponding rise of 10 percent in the ratios $V A / E$ and $K / E$, so as to keep constant the energy share. In the putty-clay economy the energy efficiency level rises (a permanent reduction in $\widehat{e}$ ) but the lifetime of capital as well as the depreciation rate of capital are unaffected. Notice that the capital to value added ratio is unaffected in all economies, which also implies that the long run level of income is not affected by the level of the energy price. This also would be the long run effect of imposing taxes on the price of energy: a permanent reduction in the use of energy.

For the sake of completeness we also describe the effect of a permanent change in the growth rate of the energy price. The effect in the putty-putty economy is very similar to a fall in the ISTC growth rate: The (detrended) ratio of value added to energy used and the energy share are left unaffected, the detrended capital to energy ratio, $K / E$, rises whereas the capital to value added ratio increases. More interesting is the effect in the putty-clay economy. A permanent increase in the growth rate of the energy price is very similar to a permanent fall in the growth rate of the extensive margin of ISTC, $\theta$. In the first place, energy efficiency increases as the efficiency level, $\widehat{e}$, falls from 0.0110 to 0.0109 . The service life of capital also falls, from 67 to 65 years. Nevertheless, the value added to energy used ratio falls, since a higher fraction of gross output is lost paying for the energy cost. This is why the energy share rises. The capital to energy ratio (detrended) falls. That is, the aggregate economy becomes less efficient. This is so because investment, which takes place in more energy efficient capital, falls.

\subsection{Dynamics of energy use and efficiency}

From the previous discussion we have learnt that the putty-putty and the putty-clay economy differ, mainly, in their response to ISTC permanent shocks and to the changes in the growth rate of the energy price. The long run response to a permanent change in the level of the energy price is the same. In order to have a sense of the differences in short-run responses we would need to study the transitional dynamics of our putty-clay economy. Tracking the dynamics of the putty-clay economy is complex since not only the distribution of capital across vintages changes along the 
transition path but the service life of capital changes, too. Hence, to analyze the dynamics of the putty-clay economy we are going to study an approximate economy where plants are always used until they disappear. That is, labor is allocated optimally in all plants but all of them are always used in production even if they yield negative profits. We do so because, given our calibration, the utilization rate of capital is very close to one, as shown in Table 5 . This is so because by the time a class of capital is not longer profitable the size of it stock remaining of that class is negligible. We have labeled such an approximate economy as the proxy putty-clay vintage capital economy, (Proxy P-C). The aggregate allocation of investment and efficiency in this economy can be found solving the following quasi-social planner's problem:

$$
\begin{array}{ll}
\max & \sum_{t=0}^{\infty} \beta^{t} \frac{c_{t}^{1-\sigma}}{1-\sigma} \\
\text { s. t. } & c_{t}+x_{t}=A_{t}\left((1+\lambda)^{t(1-\phi)} e_{t}^{\phi}(1+\theta)^{t-1}\right)^{\alpha} \mathbf{k}_{t}^{\alpha} h_{t}^{1-\alpha}-p_{t}^{e} \mathbf{e}_{t}, \\
& 0 \leq \mathbf{e}_{t+1} \leq e_{t+1}(1+\theta)^{t} x_{t}+(1-\varpi) \mathbf{e}_{t}, \\
& 0 \leq \mathbf{k}_{t+1}=x_{t}+\frac{1-\varpi}{(1+\lambda)^{1-\phi}(1+\theta)}\left(\frac{e_{t}}{e_{t+1}}\right)^{\phi} \mathbf{k}_{t}, \\
& 0 \leq x_{t}, 0 \leq e_{t+1} .
\end{array}
$$

This economy is a version of Greenwood et al. (1997) with the explicit consideration of the complementarity between capital and energy. In this economy, a change in energy efficiency of new investment, $e_{t+1}$, amounts to choosing the depreciation rate of capital. Its calibration is shown in the last column of Table 3. The long run effects of changes in ISTC and the energy price are shown in Table 6 . The main difference between the true putty-clay vintage capital economy and its proxy is that the response in energy use and efficiency with respect to ISTC changes in Scenario 2 is smaller. This is due to the fact that we are forcing the economy to use capital that is no longer profitable. Thus, we can think of the quantitative results of the proxy economy as a lower bound for the actual response of the putty-clay vintage capital economy.

We solve for the dynamics of the stationary representation of the aggregate economy in problem (5.3) with a Newton method using sparse matrices as implemented for deterministic Dynare (see Juillard, 1996), and we simulate the dynamics under perfect foresight for the various scenarios. Figures 5 and 6 show the dynamic response of the putty-putty economy and the proxy putty-clay to a permanent 10 percent increase in the energy price (solid black line) and a permanent 50 percent increase in the growth rate of ISTC (dashed blue line). Figure 5 shows the response of value added per unit of energy used, $V A / E$ (upper row), and the capital to energy ratio, $K / E$ (lower row). 
This Figure shows that the response to a permanent change in the energy price is the same in the long run, but there is no transitional dynamics in the putty-putty economy, whereas it takes a few years for the putty-clay economy to reach the new steady state. Figure 6 shows where that different transitional dynamics comes from. For one thing, the effect of the price rise on investment is stronger in the putty-putty economy. This is due to the fact that there is no possibility of substituting energy for other factors in this economy. As a result, aggregate value added falls and investment falls in order to smooth consumption, more so in the putty-clay economy. This is also why the short-run response of the capital to value added ratio is larger in the putty-clay economy. Figure 6(e) shows that even though investment, as percentage of value added falls, the efficiency of new investment jumps immediately (i.e., lower detrended energy requirement $\widehat{e}$ ).

Now we can turn to analyze the dynamic response to a permanent change in the growth rate of ISTC. Value added per unit of energy use does not change in the putty-putty economy, regardless of the scenario of energy prices (i.e., constant price or a permanent trend), whereas the response in the putty-clay economy is non-monotonic in the scenario depicted (i.e., constant energy price). The initial response is a fall in energy use (an increase in $V A / E$ ), although the capital to energy ratio, $K / E$, falls. Thus, ISTC is energy saving in the short run, whereas it is not in the long run. As shown in Figure 6(e), efficiency of new investment falls (i.e., higher energy requirement detrended $\widehat{e})$. The reason of the non monotonic behavior of $V A / E$ is that the average efficiency level of the stock falls slowly as old capital depreciates and is replaced by new capital. In the very short run this produces a boost in output (recall that less efficient capital yields more services than more efficient units), which is compensated later on by the rise in energy demand of new capital. It is also interesting to point that the response of investment is larger in the putty-clay economy. This is so because the investment channel (along with labor supply, which is not present here) is the only channel that the putty-clay economy has to accommodate any shock in the short run. This is why we view the proxy putty-cay economy as well suited to study fluctuations due to the interaction of ISTC and energy prices.

\section{Final comments}

This paper proposes a theory of investment and energy use that makes explicit the adoption of new technology when energy efficiency is embodied in capital, as the micro evidence suggests. In 
our theory the interaction between ISTC and energy prices is very complex and allows for the coexistence of gains of energy efficiency at the micro level and a rebound effect at the macro level. Expectations about the future movement of the energy price is key to find a rebound effect at the macro level after an increase in the ISTC growth rate. We think that our theory can be used to test when and how we should see a rebound effect in energy use at the aggregate level and can be used to test the aggregate effect of any policy aiming to reduce energy use.

The dynamic behavior of our model economy can be studied by means of an approximate aggregate two sector economy where the depreciation rate of capital is endogenous and depends on the level of energy efficiency built in investment. The study of the transitional dynamics of this economy shows that the interaction of ISTC and energy prices have a very non linear effect on the choice of energy efficiency and investment in the short run. Thus, this model economy seems a promising tool to analyze the quantitative effect of the interplay of ISTC innovations and energy prices on aggregate fluctuations.

In this paper we have assumed that Investment Specific Technical innovations arrive exiguously to focus our attention on how the interplay of ISTC and energy prices shape the energy efficiency decision. A natural extension would be to endogenize the size of ISTC innovations. This is a complex objective since differentiating the dual nature of ISTC (i.e., innovations at the extensive or the intensive margin) is important. We leave this for future research. We have also abstracted from climate change and the existence of clean (non fuel based) technologies. We have done so in order to isolate the effects on energy efficiency of the interplay of ISTC and energy prices. This will be essential to study the effect of environmental policies and leave it for further research. 


\section{Appendix}

\section{A Data and Calibration}

In this Appendix we document the construction of the data series we use in the empirical part of the paper. We obtain data from two sources: the Annual Energy Review (2000) and National Income and Product Accounts. The data we use can be accessed in the addresses: http://www.eia.gov/ and http://www.bea.gov. From now on we will refer to each source as AER, and NIPA, respectively. Our data set is available upon request.

\section{A.1 Energy price, use, and expenditures series}

Our energy data covers the primary energy consumption of end-users and is obtained from the Annual Energy Review (AER, hereafter). We consider four forms of energy: coal, petroleum, natural gas and electricity. AER (Table 2.1a) gives data on total energy consumption by end users measured in British termal units (BTUs) disaggregated into the four forms of energy considered. We denote these data on energy consumption for each type of energy by $Q_{i t}$, where the index $i$ denotes the form of energy.

This measure $Q_{i t}$ is already net of energy consumption of the electricity sector. We subtract from total primary energy consumption of the industrial sector that of four energy sectors: oil and gas extraction, electricity and gas services, petroleum and coal production, and pipeline transportation. The BEA gives information on the net stock of Fixed Assets by industry and we assume that the amount of BTUs consumed by those four sectors, as a proportion of BTUs consumed by the industrial sector, is the same that the amount of capital in those sectors as a proportion of assets in the industrial sector. We define total energy use as $E_{t}=\sum_{i} Q_{i t}$, where $Q_{i t}$ is the amount of BTUs yielded by each type of energy consumed. $P_{i t}$ is the price in dollars per BTUs of energy type, divided by the implicit price deflator of non durable consumption goods and services in NIPA (which is constructed as a weighted average of the two implicit price deflators). For coal, natural gas and petroleum we use the production price series (AER, Table 3.1). For electricity, we use the retail price of electricity sold by electric utilities (see AER, Table 8.10). In Table 8.10 the price for electricity is in cents per kilowatt-hour. We use AER Table A.6 to convert the price to cents per BTUs. All prices are in real terms; i.e., divided by the implicit price deflator of non durable consumption goods and services. We construct the energy price deflator as

$$
p_{t}=\frac{\sum_{i} Q_{i t} P_{i t}}{\sum_{i} Q_{i t}} \text {. }
$$

Finally, energy expenditure is $p_{t} \cdot E_{t}=\sum_{i} Q_{i t} P_{i t}$.

\section{A.2 Output, consumption, investment, and the capital stock}

We follow the method described by Cooley and Prescott (1995) to construct broad measures of output, consumption, investment, and the capital stock. Specifically, our measure of capital includes 
private stock of capital, the stock of inventories, the stock of consumer durable goods and the government stock. Consequently, the measured value of GDP is augmented with the imputed flow of services from the stock of durable goods and the government stock. We subtract from each of the series of output, investment and capital the corresponding series for the energy producing sectors: oil and gas extraction, electricity and gas services, petroleum and coal production, and pipeline transportation, as our theory cannot account for the behavior of the energy-producing sectors. We have information on the three variables for the last two sectors but about the first two sectors we only have information about the net stock of capital, and we use it to impute estimates of output and investment. Gross output is the sum of value added and the final expenditure on energy. Real variables are obtained by dividing the nominal variables by the implicit price deflator of non durable consumption goods and services.

\section{B Energy use and ISTC across countries}

We obtain the cross sectional data from two sources: the International Energy Association, IEA (2011), and the Penn-World Table (version 7.1) at the worldwide level. We select a sample of OECD countries over the period 1970-2010. Our cross sectional data set is also available upon request. ${ }^{6}$

The energy intensity variable is defined again as total energy in BTUs (TOEs) over GDP (real and PPP adjusted). Per capita measures are obtained using the population measures in the PWT 7.1. The price of investment variable is the one in the PWT as well: PPP over investment divided by national currency units per US dollar. Finally the energy and sectoral mixes for each country and each year are obtained from the IEA (2011).

We use intervals of 5 years (annualized data, instruments are always lags from previous period) to characterize the relationship between growth in energy intensity and past energy intensity levels. We obtain OLS estimates from

$$
G E I_{i, t}=\alpha+\phi^{\prime} T_{t}-\beta E I_{i, t-s}+\delta Y_{i, t-s}+\varphi G Y_{i, t-s}+\lambda^{\prime} X_{i t}+\varepsilon_{i, t}
$$

where the dependent variable $G E I$, which is the growth rate in energy intensity, is regressed over a constant term and time dummies, together with the log energy intensity $(E I)$, the $\log G D P$ per capita $(Y)$, and GDP per capita growth $(G Y)$, all lagged, and a set of controls $X$ affecting $G E I$ that are time and country specific, and that include the log of the price of investment $(P I)$ and its growth $(G P I)$, and the changes in the energy mix and the sectoral mix. More precisely:

$$
\lambda^{\prime} X_{i t} \equiv \theta P I_{i, t-s}+\eta G P I_{i, t-s}+\sum_{j=1}^{J-1} \delta_{j} m_{j i t}+\sum_{k=1}^{K-1} \tau_{k} s_{k i t}
$$

where each $m_{j}$ is the change in share in the primary mix (coal to primary energy source $j$ ) and each $s_{k}$ is the change in share in the final mix (industry to final sectoral use $k$ ).

\footnotetext{
${ }^{6}$ OECD countries selection excludes LUX and the emerging countries: CHL, EST, ISL, ISR, LVA, MEX, SVK, SVN, TUR. This appendix follows the description of the data and part of the methods in Díaz et al. (2014)
} 


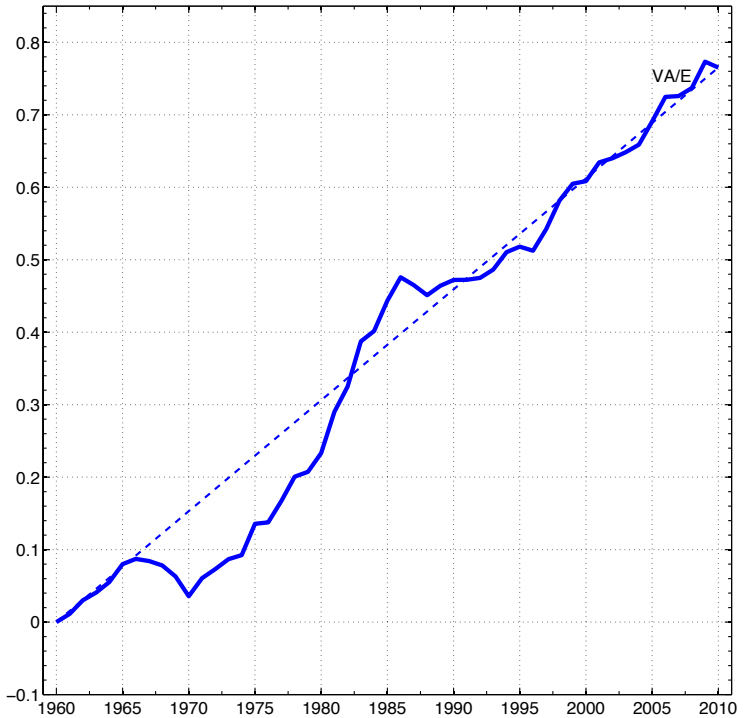

(a) Value added per unit of energy use, $V A / E$, in logs.

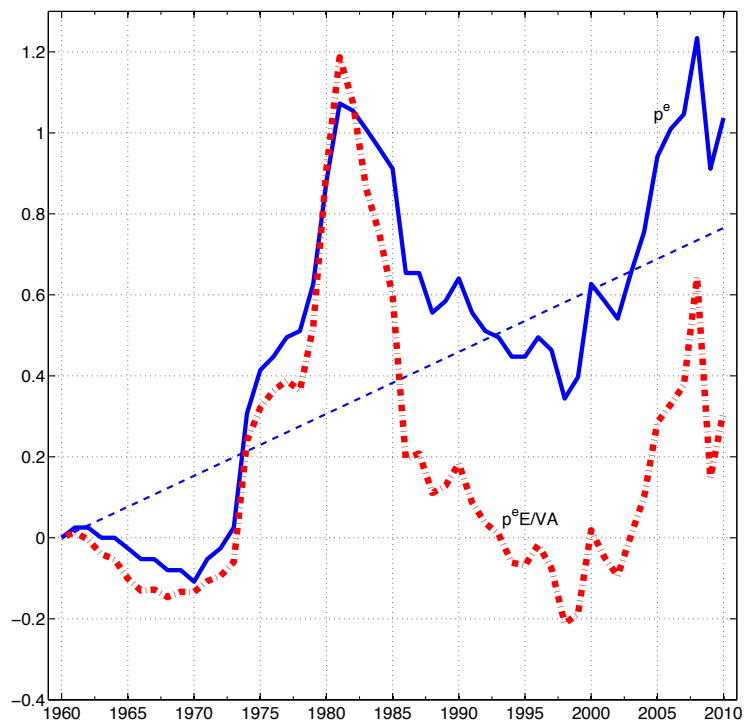

(c) The logged energy price, $p$ and the share of energy, $p^{e} E / V A$.

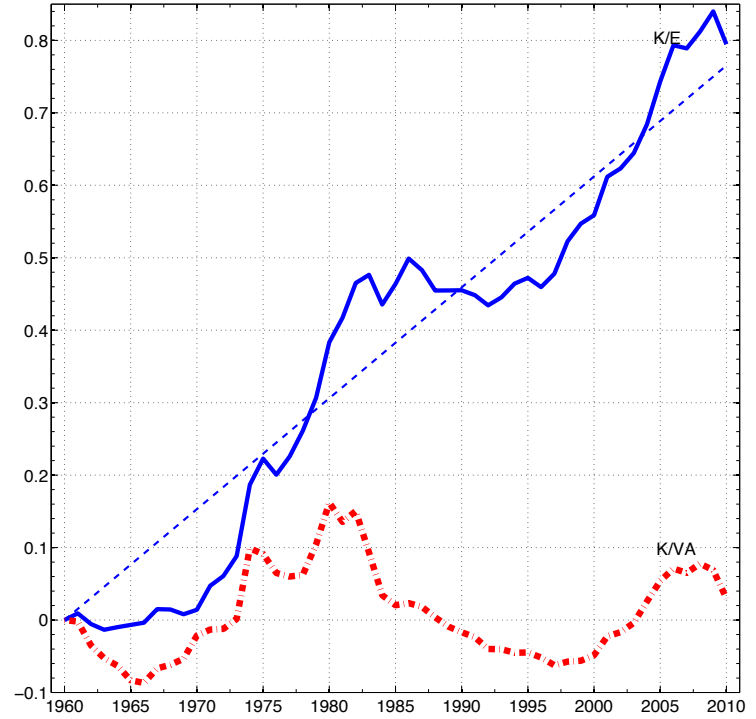

(b) Capital-energy ratio, $K / E$, in logs, and capital to value added ratio, $K / V A$.

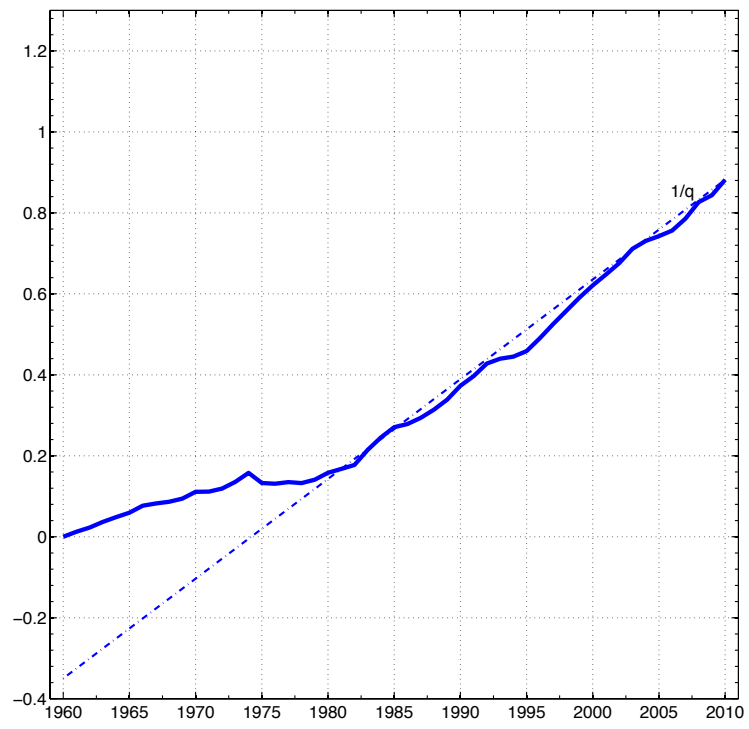

(d) The logged relative price of investment goods, $1 / q$.

Figure 1: Energy use and energy efficiency in the US economy. 


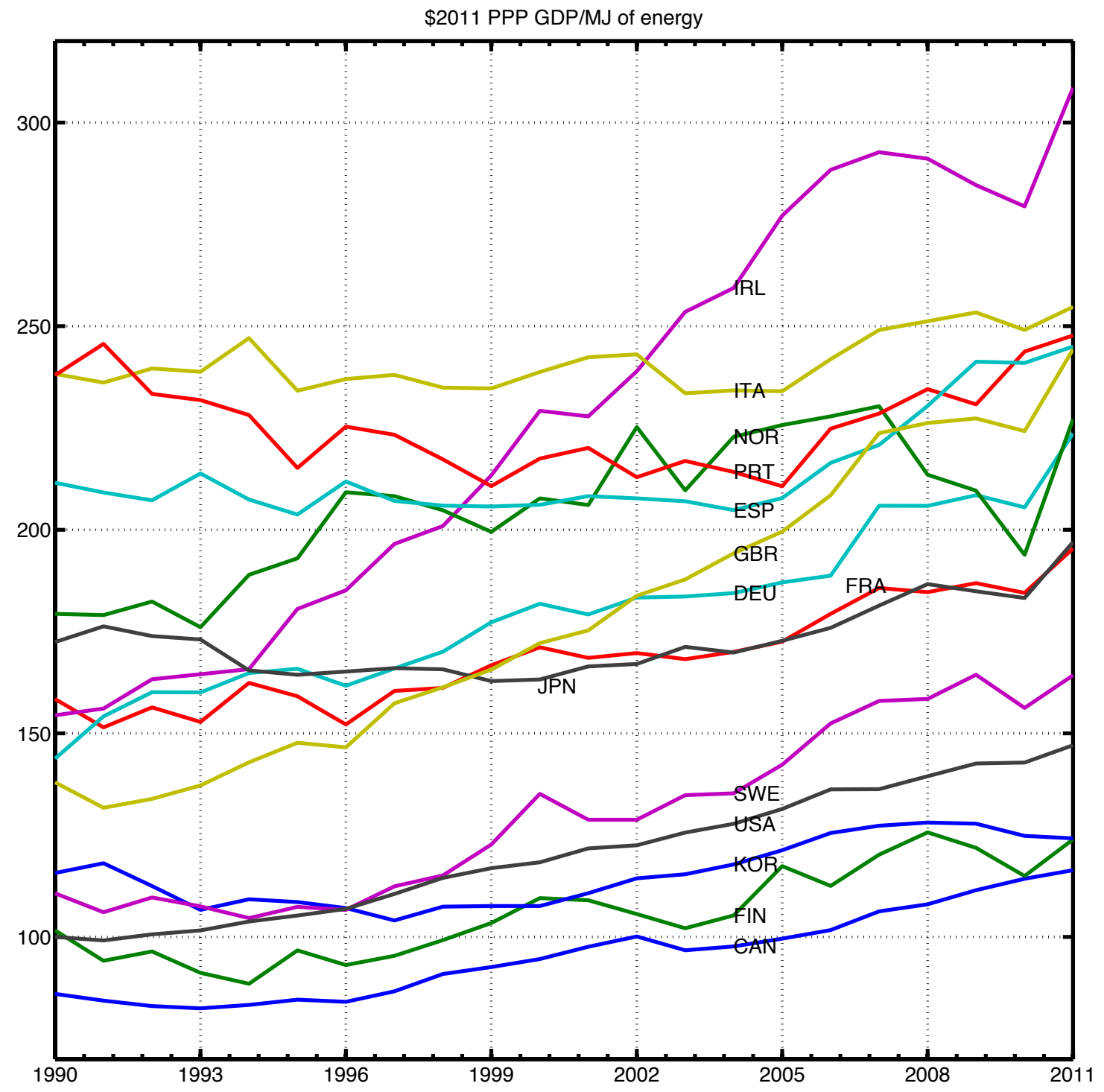

Figure 2: Energy use across various OECD countries 


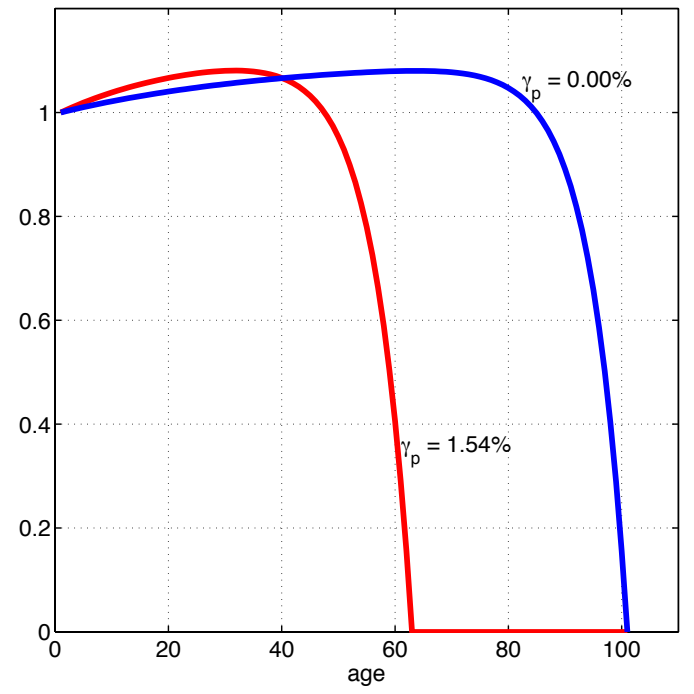

(a) $p_{t}\left(z, e_{z}\right) / q_{t}\left(z, e_{z}\right)$ by age.

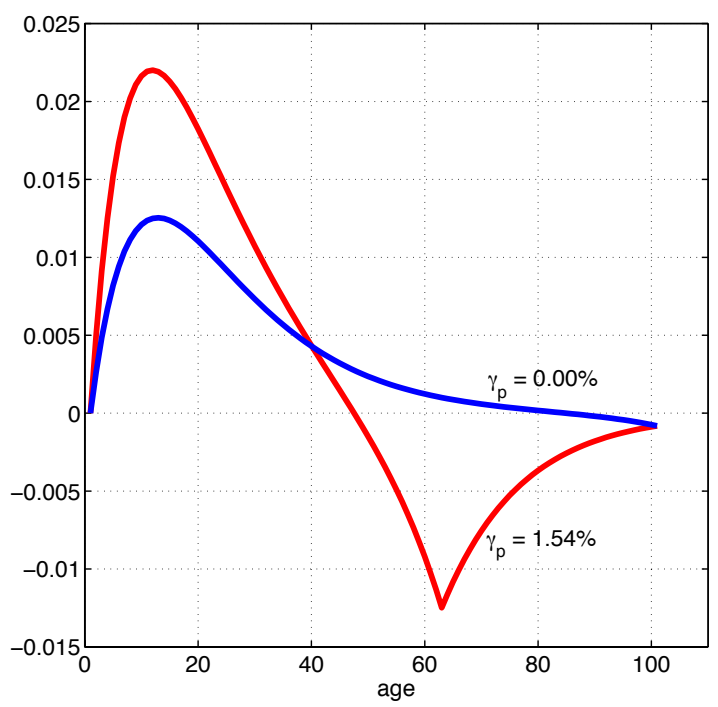

(b) $\left(\frac{p_{t}\left(z, e_{z}\right)}{q_{t}\left(z, e_{z}\right)}-1\right)(1-\varpi)^{t-z}$.

Figure 3: Market price, $p_{t}\left(z, e_{z}\right)$, versus price in units of gross output, $q_{t}\left(z, e_{z}\right)$ in the balanced growth path. 


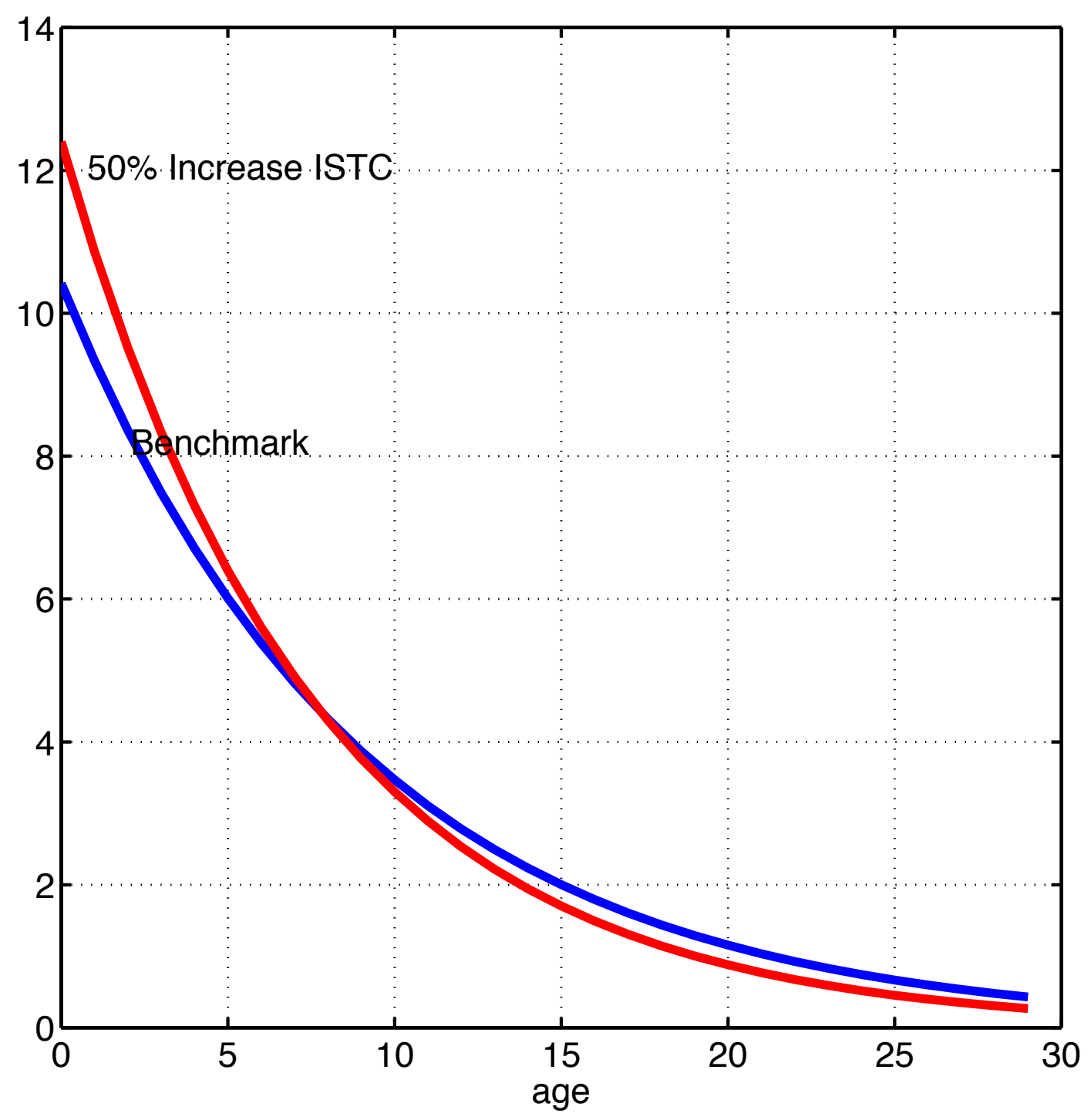

Figure 4: Labor allocation across vintages 


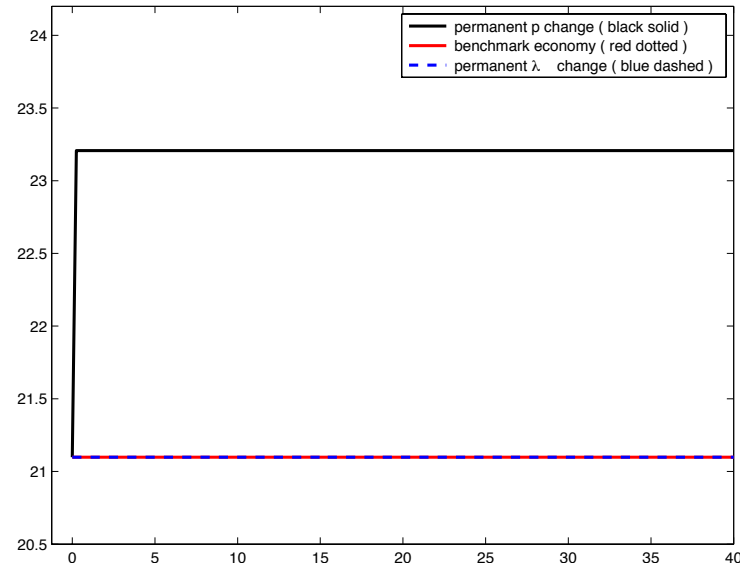

(a) Putty-putty, $V A / E$

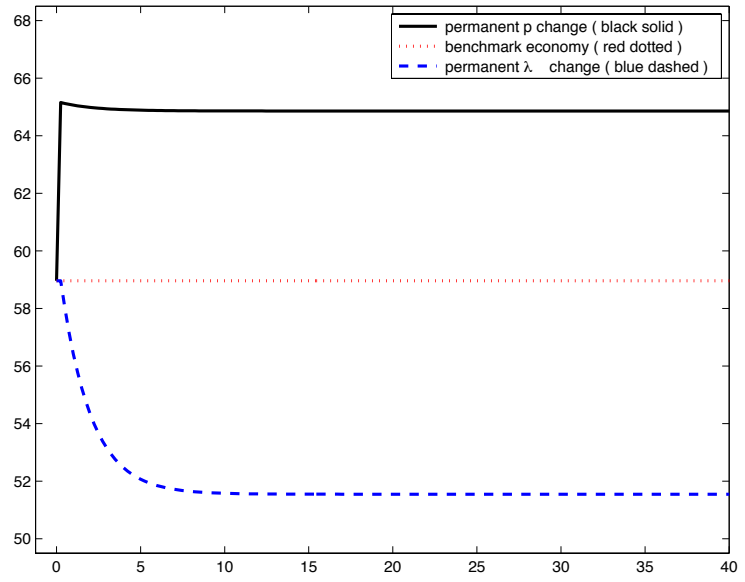

(c) Putty-putty, $K / E$.

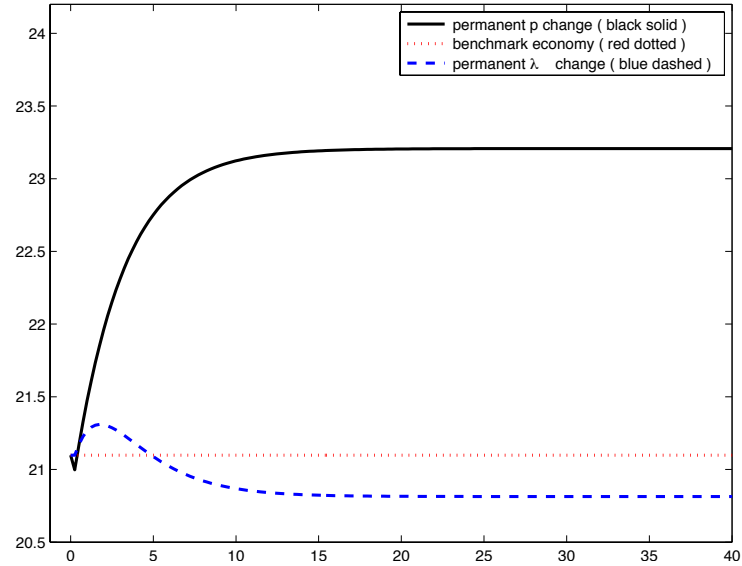

(b) Putty-clay, $V A / E$.

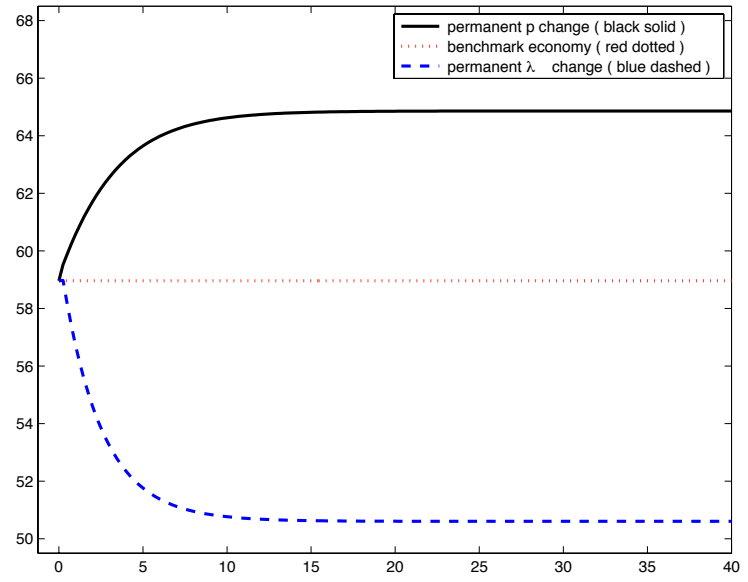

(d) Putty-clay, $K / E$.

Figure 5: Responses to either a permanent 10\% shock in the price of energy, $p^{e}$, or a permanent $50 \%$ shock in ISTC growth in either $\theta$ or $\lambda(\mathrm{I})$. 


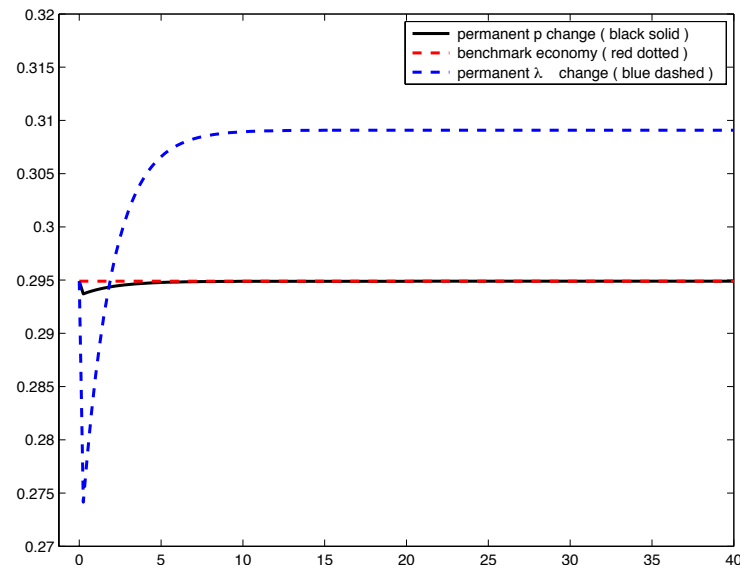

(a) Putty-putty, $X / V A$.

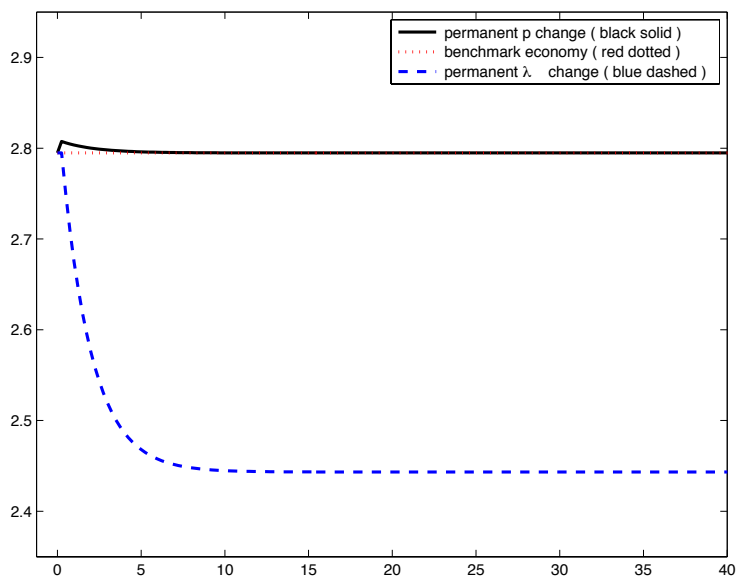

(c) Putty-putty, $K / V A$.

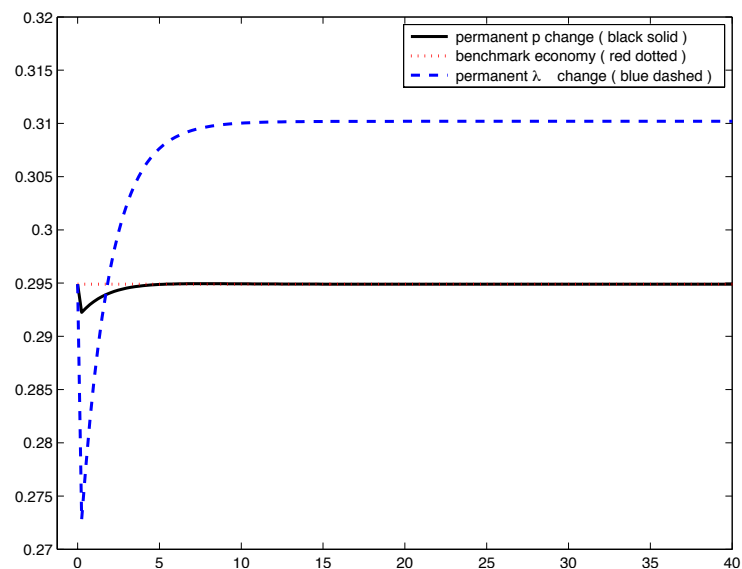

(b) Putty-clay, $X / V A$.

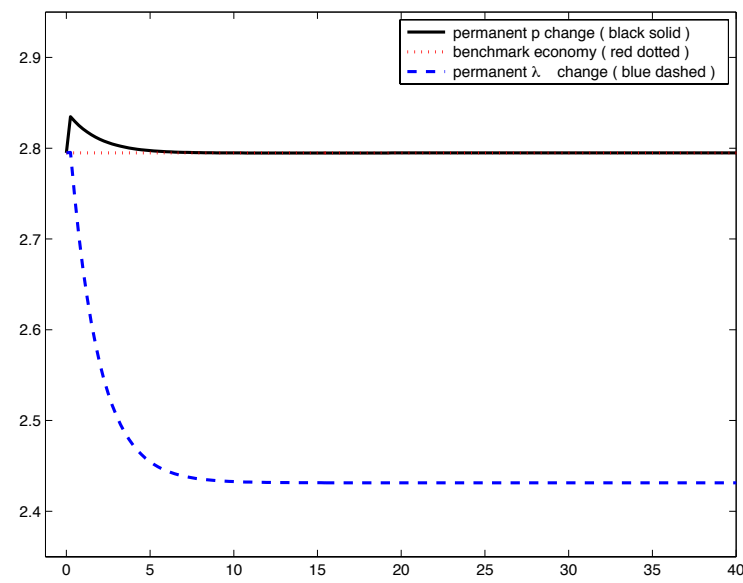

(d) Putty-clay, $K / V A$.

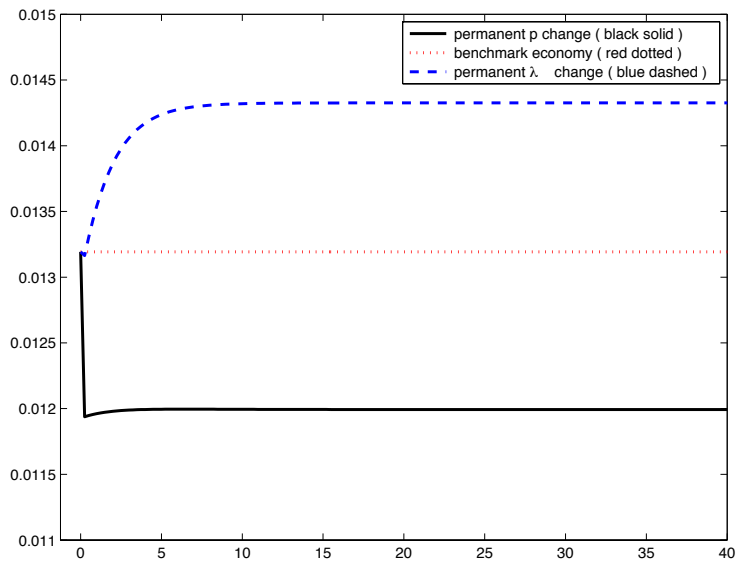

(e) Putty-clay, $\widehat{e}$.

Figure 6: Responses to either a permanent $10 \%$ shock in the price of energy, $p^{e}$, or a permanent $50 \%$ shock in ISTC growth in either $\theta$ or $\lambda$ (II). 


\begin{tabular}{|c|c|c|c|c|c|c|c|}
\hline & (1) & (2) & $(3)$ & $(4)$ & $(5)$ & $(6)$ & $(7)$ \\
\hline$e_{t-1} / g d p_{t-1}$ & $\begin{array}{l}-0.0030^{* * *} \\
(-3.42)\end{array}$ & $\begin{array}{l}-0.0033^{* * *} \\
(-3.63)\end{array}$ & $\begin{array}{l}-0.0027^{* * *} \\
(-3.10)\end{array}$ & $\begin{array}{l}-0.0026^{* * *} \\
(-3.13)\end{array}$ & $\begin{array}{l}-0.0024^{* *} \\
(-2.57)\end{array}$ & $\begin{array}{l}-0.0023^{* * *} \\
(-2.78)\end{array}$ & $\begin{array}{l}-0.0038^{* * *} \\
(-3.56)\end{array}$ \\
\hline$g d p_{t} / g d p_{t-1}$ & $\begin{array}{l}-0.4880^{* * *} \\
(-3.25)\end{array}$ & & $\begin{array}{l}-0.4640^{* * *} \\
(-3.06)\end{array}$ & $\begin{array}{l}-0.4500^{* * *} \\
(-2.92)\end{array}$ & $\begin{array}{l}-0.4760^{* * *} \\
(-2.85)\end{array}$ & $\begin{array}{l}-0.4730^{* * *} \\
(-2.85)\end{array}$ & $\begin{array}{l}-0.4340^{* * *} \\
(-2.72)\end{array}$ \\
\hline$g d p_{t-1}$ & $\begin{array}{l}0.0042 \\
(1.10)\end{array}$ & & $\begin{array}{l}0.0142^{* *} \\
(2.46)\end{array}$ & $\begin{array}{l}0.0138^{* *} \\
(2.37)\end{array}$ & $\begin{array}{l}0.0130^{* *} \\
(2.00)\end{array}$ & $\begin{array}{l}0.0122^{*} \\
(1.88)\end{array}$ & $\begin{array}{l}-0.0104^{* * *} \\
(-2.65)\end{array}$ \\
\hline$q_{t} / q_{t-1}$ & & $\begin{array}{l}-0.0302 \\
(-0.59)\end{array}$ & $\begin{array}{l}-0.0821^{*} \\
(-1.69)\end{array}$ & $\begin{array}{l}-0.0824^{*} \\
(-1.70)\end{array}$ & $\begin{array}{l}-0.0409 \\
(-0.88)\end{array}$ & $\begin{array}{l}-0.0353 \\
(-0.77)\end{array}$ & $\begin{array}{l}0.0579^{*} \\
(1.89)\end{array}$ \\
\hline$q_{t-1}$ & & $\begin{array}{l}0.0044 \\
(0.76)\end{array}$ & $\begin{array}{l}-0.0172^{* *} \\
(-2.36)\end{array}$ & $\begin{array}{l}-0.0175^{* *} \\
(-2.38)\end{array}$ & $\begin{array}{l}-0.0124^{*} \\
(-1.62)\end{array}$ & $\begin{array}{l}-0.0131^{*} \\
(-1.75)\end{array}$ & $\begin{array}{l}0.0105^{*} \\
(1.78)\end{array}$ \\
\hline cons & $\begin{array}{l}0.0050 \\
(0.14)\end{array}$ & $\begin{array}{l}0.0049 \\
(0.19)\end{array}$ & $\begin{array}{l}-0.0159 \\
(-0.40)\end{array}$ & $\begin{array}{l}-0.0091 \\
(-0.22)\end{array}$ & $\begin{array}{l}-0.0247 \\
(-0.58)\end{array}$ & $\begin{array}{l}-0.0111 \\
(-0.25)\end{array}$ & $\begin{array}{l}0.0711^{*} \\
(1.83)\end{array}$ \\
\hline $\operatorname{dum}_{75}$ & $\begin{array}{l}0.0082 \\
(1.32)\end{array}$ & $\begin{array}{l}0.0088 \\
(1.56)\end{array}$ & $\begin{array}{l}0.0057 \\
(0.92)\end{array}$ & $\begin{array}{l}0.0043 \\
(0.66)\end{array}$ & $\begin{array}{l}0.0042 \\
(0.55)\end{array}$ & $\begin{array}{l}0.0053 \\
(0.64)\end{array}$ & \\
\hline $\operatorname{dum}_{80}$ & $\begin{array}{l}-0.0272^{* * *} \\
(-3.80)\end{array}$ & $\begin{array}{l}-0.0159^{* *} \\
(-2.49)\end{array}$ & $\begin{array}{l}-0.0255^{* * *} \\
(-3.64)\end{array}$ & $\begin{array}{l}-0.0281^{* * *} \\
(-4.03)\end{array}$ & $\begin{array}{l}-0.0278^{* * *} \\
(-3.22)\end{array}$ & $\begin{array}{l}-0.0290^{* * *} \\
(-3.44)\end{array}$ & \\
\hline dum $_{85}$ & $\begin{array}{l}-0.0259^{* * *} \\
(-4.42)\end{array}$ & $\begin{array}{l}-0.0172^{* * *} \\
(-3.33)\end{array}$ & $\begin{array}{l}-0.0237^{* * *} \\
(-4.15)\end{array}$ & $\begin{array}{l}-0.0276^{* * *} \\
(-4.66)\end{array}$ & $\begin{array}{l}-0.0227^{* * *} \\
(-3.09)\end{array}$ & $\begin{array}{l}-0.0263^{* * *} \\
(-3.41)\end{array}$ & \\
\hline dum $_{90}$ & $\begin{array}{l}-0.0405^{* * *} \\
(-5.87)\end{array}$ & $\begin{array}{l}-0.0291^{* * *} \\
(-3.73)\end{array}$ & $\begin{array}{l}-0.0463^{* * *} \\
(-5.61)\end{array}$ & $\begin{array}{l}-0.0510^{* * *} \\
(-6.12)\end{array}$ & $\begin{array}{l}-0.0439 * * * \\
(-4.40)\end{array}$ & $\begin{array}{l}-0.0474^{* * *} \\
(-4.86)\end{array}$ & \\
\hline $\operatorname{dum}_{95}$ & $\begin{array}{l}-0.0411^{* * *} \\
(-5.16)\end{array}$ & $\begin{array}{l}-0.0296^{* * *} \\
(-3.75)\end{array}$ & $\begin{array}{l}-0.0429^{* * *} \\
(-4.95)\end{array}$ & $\begin{array}{l}-0.0450^{* * *} \\
(-5.41)\end{array}$ & $\begin{array}{l}-0.0402^{* * *} \\
(-3.82)\end{array}$ & $\begin{array}{l}-0.0421^{* * *} \\
(-4.10)\end{array}$ & \\
\hline $\operatorname{dum}_{00}$ & $\begin{array}{l}-0.0427^{* * *} \\
(-4.12)\end{array}$ & $\begin{array}{l}-0.0259^{* * *} \\
(-3.09)\end{array}$ & $\begin{array}{l}-0.0451^{* * *} \\
(-4.27)\end{array}$ & $\begin{array}{l}-0.0466^{* * *} \\
(-4.77)\end{array}$ & $\begin{array}{l}-0.0447^{* * *} \\
(-3.62)\end{array}$ & $\begin{array}{l}-0.0450^{* * *} \\
(-3.86)\end{array}$ & \\
\hline $\operatorname{dum}_{05}$ & $\begin{array}{l}-0.0477^{* * *} \\
(-7.12)\end{array}$ & $\begin{array}{l}-0.0419^{* * *} \\
(-6.12)\end{array}$ & $\begin{array}{l}-0.0552^{* * *} \\
(-7.02)\end{array}$ & $\begin{array}{l}-0.0571^{* * *} \\
(-7.30)\end{array}$ & $\begin{array}{l}-0.0520^{* * *} \\
(-5.37)\end{array}$ & $\begin{array}{l}-0.0522^{* * *} \\
(-5.54)\end{array}$ & \\
\hline $\operatorname{dum}_{10}$ & $\begin{array}{l}-0.0433^{* * *} \\
(-6.47)\end{array}$ & $\begin{array}{l}-0.0270^{* * *} \\
(-5.13)\end{array}$ & $\begin{array}{l}-0.0482^{* * *} \\
(-6.45)\end{array}$ & $\begin{array}{l}-0.0500^{* * *} \\
(-6.92)\end{array}$ & $\begin{array}{l}-0.0478^{* * *} \\
(-4.99)\end{array}$ & $\begin{array}{l}-0.0493^{* * *} \\
(-5.24)\end{array}$ & \\
\hline $\begin{array}{l}\text { Num. Obs. } \\
\mathrm{R}^{2}\end{array}$ & $\begin{array}{l}210 \\
0.4230\end{array}$ & $\begin{array}{l}210 \\
0.3010\end{array}$ & $\begin{array}{l}210 \\
0.4340\end{array}$ & $\begin{array}{l}210 \\
0.4360\end{array}$ & $\begin{array}{l}189 \\
0.4280\end{array}$ & $\begin{array}{l}189 \\
0.4410\end{array}$ & $\begin{array}{l}189 \\
0.2540\end{array}$ \\
\hline
\end{tabular}

Notes: Data for a panel of OECD countries during the period 1970-2010. All variables are in logs.

Table 1: Estimation 


\begin{tabular}{|c|c|c|c|c|c|c|c|}
\hline & $(1)$ & $(2)$ & $(3)$ & (4) & (5) & (6) & $(7)$ \\
\hline \multicolumn{8}{|l|}{$(\ldots)$} \\
\hline \multirow[t]{2}{*}{$\operatorname{mixc} 2$} & & & & -0.0387 & & -0.0585 & $0.0604^{*}$ \\
\hline & & & & $(-1.00)$ & & $(-1.41)$ & $(1.66)$ \\
\hline \multirow[t]{2}{*}{$\operatorname{mixc} 3$} & & & & -0.0073 & & -0.0681 & -0.0411 \\
\hline & & & & $(-0.17)$ & & $(-1.42)$ & $(-0.88)$ \\
\hline \multirow[t]{2}{*}{$\operatorname{mixc} 4$} & & & & -0.0066 & & -0.0150 & 0.0871 \\
\hline & & & & $(-0.14)$ & & $(-0.28)$ & $(1.60)$ \\
\hline \multirow[t]{2}{*}{ mixc5 } & & & & $-0.1090^{*}$ & & $-0.1680^{* *}$ & $-0.2200 * *$ \\
\hline & & & & $(-1.77)$ & & $(-2.27)$ & $(-2.41)$ \\
\hline \multirow[t]{2}{*}{$\operatorname{mixcf2}$} & & & & & $-0.2480 * * *$ & $-0.2540 * * *$ & $-0.3830 * * *$ \\
\hline & & & & & $(-2.91)$ & $(-2.98)$ & $(-4.01)$ \\
\hline \multirow[t]{2}{*}{ mixcf3 } & & & & & 0.0108 & -0.0075 & 0.0411 \\
\hline & & & & & $(0.21)$ & $(-0.15)$ & $(0.71)$ \\
\hline \multirow[t]{2}{*}{ mixcf4 } & & & & & -0.0486 & -0.0309 & 0.0118 \\
\hline & & & & & $(-1.16)$ & $(-0.76)$ & $(0.27)$ \\
\hline \multirow[t]{2}{*}{$\operatorname{mixcf5}$} & & & & & $-0.3950 * * *$ & $-0.4290 * * *$ & $-0.3520 * *$ \\
\hline & & & & & $(-2.68)$ & $(-2.98)$ & $(-2.18)$ \\
\hline \multirow[t]{2}{*}{ mixcf6 } & & & & & 0.0765 & 0.0872 & 0.0795 \\
\hline & & & & & $(1.07)$ & $(1.17)$ & $(1.08)$ \\
\hline \multirow{2}{*}{$\begin{array}{l}\text { Num. Ob. } \\
\text { R2 }\end{array}$} & 210 & 210 & 210 & 210 & "189 & " 189 & " 189 \\
\hline & 0.4230 & 0.3010 & 0.4340 & 0.4360 & 0.4280 & 0.4410 & 0.2540 \\
\hline
\end{tabular}

Notes: Data for a panel of OECD countries during the period 1070-2010. The mix refers to source (oil c2; gas c3; nuclear c4; renewables c5) and sector (transport cf2; household cf3; services cf4; agriculture cf5).

Table 2: Estimation (continued)

\begin{tabular}{|c|c|c|c|c|}
\hline Param. & Observation & Putty-Putty & Putty-Clay & Proxy P-C \\
\hline$\sigma$ & - & 1.0000 & 1.0000 & 1.000 \\
\hline$\alpha$ & $w L / V A=0.5845$ & 0.4419 & 0.4419 & 0.4419 \\
\hline$p^{e}$ & - & 1.0000 & 1.0000 & 1.0000 \\
\hline$\varpi$ & $=0.2949$ & 0.0693 & 0.0693 & 0.0693 \\
\hline \multicolumn{5}{|c|}{ Scenario 1: No trend in the energy price, $\gamma_{p}=0.0000$} \\
\hline$\beta$ & $K / V A=2.7948$ & 0.9591 & 0.9580 & 0.9579 \\
\hline$\phi$ & $p^{e} E / V A=0.0474$ & 0.1024 & 0.0949 & 0.0944 \\
\hline & $=0.0127$ & -0.0030 & -0.0042 & -0.0042 \\
\hline$(1+\lambda)(1+\theta)$ & $=1.0258$ & 1.0258 & 1.0286 & 1.0286 \\
\hline \multicolumn{5}{|c|}{ Scenario 2: Positive trend in the energy price, $\gamma_{p}=0.0154$} \\
\hline$\beta$ & $K / V A=2.7948$ & 0.9591 & 0.9573 & 0.9569 \\
\hline$\phi$ & $p^{e} E / V A$ & 0.1024 & 0.0902 & 0.0876 \\
\hline & $=0.0127$ & -0.0024 & -0.0042 & -0.0042 \\
\hline$(1+\lambda)(1+\theta)$ & $=1.0258$ & 1.0258 & 1.0311 & 1.0299 \\
\hline
\end{tabular}

Notes: Averages for period 1960-2010. $u(c)=\ln c, V A=$ measured GDP + services of consumer durables + services of public capital - VA of energy producing sectors.

Table 3: Calibration 


\begin{tabular}{l|rrrrr}
\hline \hline & $V A / E$ & $p E / V A$ & $K / E$ & $K / V A$ & $X / V A$ \\
\hline \multicolumn{7}{c}{$50 \% \Delta$ in ISTC } \\
\hline Putty-Putty (S1 \& S2) & 0.0000 & 0.0000 & -12.2310 & -12.2310 & 4.6801 \\
Putty-Clay (S1) & -1.1879 & 1.2022 & -13.6702 & -12.6323 & 5.0258 \\
Putty-Clay(S2) & 0.6681 & -0.6637 & -12.6650 & -13.2446 & 5.2328 \\
\hline \multicolumn{7}{c}{$10 \%$} & in $p^{e}$ \\
\hline All economies & 10.0000 & 0.0000 & 10.0000 & 0.0000 & 0.0000 \\
\hline \multicolumn{7}{c}{$10 \%$} & $\Delta$ in $\gamma_{p}$ & & & \\
\hline Putty-Putty (S2) & 0.0000 & 0.0000 & 0.0875 & 0.0875 & -0.0307 \\
Putty-Clay (S2) & -0.6589 & 0.6633 & -0.4721 & 0.1880 & -0.0344 \\
\hline
\end{tabular}

Notes: Percent changes with respect to the calibrated balanced growth path.

Table 4: Long run effects in aggregate energy use and energy efficiency.

\begin{tabular}{l|rrrrr}
\hline \hline & $T$ & $\widehat{e}$ & $u$ & $u^{e}$ & $\delta$ \\
\hline Senchmark & 100.0000 & 0.0133 & 1.0000 & 0.9998 & 0.0928 \\
$50 \% \Delta$ in ISTC & 68.0000 & 0.0144 & 0.9999 & 0.9984 & 0.1040 \\
$10 \% \Delta$ in $p^{e}$ & 100.0000 & 0.0120 & 1.0000 & 0.9998 & 0.0928 \\
\hline \multicolumn{7}{|c}{ Scenario 2} \\
\hline Benchmark & 67.0000 & 0.0110 & 0.9994 & 0.9903 & 0.0927 \\
$50 \% \Delta$ in ISTC & 51.0000 & 0.0121 & 0.9989 & 0.9827 & 0.1046 \\
$10 \% \Delta$ in $p^{e}$ & 67.0000 & 0.0100 & 0.9994 & 0.9903 & 0.0927 \\
$10 \% \Delta$ in $\gamma_{p}$ & 65.0000 & 0.0109 & 0.9992 & 0.9876 & 0.0926 \\
\hline
\end{tabular}

Table 5: Long run effects in service life and efficiency in the Putty-Clay Vintage economy.

\begin{tabular}{l|rrrrrr}
\hline \hline & $V A / E$ & $p E / V A$ & $K / E$ & $K / V A$ & $X / V A$ & $\widehat{e}$ \\
\hline $50 \% \Delta$ in ISTC(S1) & -1.3159 & 1.3334 & -13.7714 & -12.6216 & 5.0386 & 8.3036 \\
$50 \% \Delta$ in ISTC (S2) & 0.0526 & -0.0526 & -13.1183 & -13.1640 & 5.2914 & 9.7647 \\
$10 \% \Delta$ in $p^{e}$ (S1 \& S2) & 10.0000 & 0.0000 & 10.0000 & 0.0000 & 0.0000 & -9.0909 \\
$10 \% \Delta$ in $\gamma_{p}$ (S2) & -0.9039 & 0.9121 & -0.7104 & 0.1952 & -0.0207 & -1.5147 \\
\hline
\end{tabular}

Notes: Percent changes with respect to the calibrated balanced growth path.

Table 6: Long run effects in the Proxy Putty-Clay Vintage economy. 


\section{References}

Acemoglu, D. (2002). Directed technical change. Review of Economic Studies, 9(4):781-809.

Acemoglu, D., Aghion, P., Bursztyn, L., and Hemous, D. (2012). The environment and directed technical change. American Economic Review, 102(1):131-66.

Atkeson, A. and Kehoe, P. J. (1999). Models of energy use: Putty-putty versus putty-clay. American Economic Review, 89(4):1028-43.

Cooley, T. F. and Prescott, E. C. (1995). Economic growth and business cycles. In Cooley, T. F., editor, Frontiers of Business Cycle Research, chapter 1, pages 1-38. Princeton University Press, Princeton.

Cummins, J. G. and Violante, G. L. (2002). Investment-Specific Technical Change in the US (1947-2000): Measurement and macroeconomic consequences. Review of Economic Dynamics, $5(2): 243-284$.

Díaz, A., Marrero, G. A., and Puch, L. A. (2014). Co2 emissions, energy technologies and the macroeconomy. Mimeo, Universidad Carlos III de Madrid.

Díaz, A., Puch, L. A., and Guilló, M. D. (2004). Costly capital reallocation and energy use. Review of Economic Dynamics, 7(2):494-518.

Frondel, M., Ritter, N., and Vance, C. (2012). Heterogeneity in the rebound effect: Further evidence for germany. Energy Economics, 34:461 - 467.

Gillingham, K., Rapson, D., and Wagner, G. (2016). The rebound effect and energy efficiency policy. Review of Environmental Economics and Policy, 10(1):68 - 88.

Gordon, R. J. (1990). The Measurement of Durable Goods Prices. National Bureau of Economic Research Monograph Series, Chicago: University of Chicago Press.

Gordon, R. J. (1996). NBER Macroeconomics Annual, volume 11, chapter Can Technology Improvements Cause Productivity Slowdowns?: Comment, pages 259-267. The University of Chicago Press.

Greenwood, J., Hercowitz, Z., and Krusell, P. (1997). Long-run implications of investment-specific technological change. American Economic Review, 87(3):342-62.

Hassler, J., Krusell, P., and Olovsson, C. (2012). Energy-saving technical change. Working Paper 18456, National Bureau of Economic Research.

IEA (2011). International Economic Association, World Energy Outlook, OECD/IEA, Paris.

Juillard, M. (1996). Dynare : a program for the resolution and simulation of dynamic models with forward variables through the use of a relaxation algorithm. CEPREMAP Working Papers (Couverture Orange) 9602, CEPREMAP.

Knittel, C. R. (2011). Automobiles on steroids: Product attribute trade-offs and technological progress in the automobile sector. American Economic Review, 101(7):3368-99.

Newell, R. G., Jaffe, A. B., and Stavins, R. N. (1999). The induced innovation hypothesis and energy-saving technological change. The Quarterly Journal of Economics, 114(3):941-975. 
Pindyck, R. S. and Rotemberg, J. J. (1983). Dynamic factor demands and the effects of energy price shocks. American Economic Review, 73(5):1066-79.

Popp, D. (2002). Induced innovation and energy prices. American Economic Review, 92(1):160-180.

Rodríguez-López, J. and Torres, J. L. (2012). Technological sources of productivity growth In Germany, Japan, and the United States. Macroeconomic Dynamics, 16(01):133-150.

Sato, K. (1976). The meaning and measurement of the real value added index. The Review of Economics and Statistics, 58(4):434-442.

Solow, R. M. (1960). Mathematical Methods in Social Sciences, 1959: Proceedings of the First Stanford Symposium, chapter Investment and technological progress, pages 89-104. Stanford University Press.

Steinbuks, J. and Neuhoff, K. (2010). Operational and investment response to energy prices in the OECD manufacturing sector. Cambridge Working Papers in Economics 1015, Faculty of Economics, University of Cambridge. 